Article

\title{
A Novel Method for Analyzing Highly Renewable and Sector-Coupled Subnational Energy Systems-Case Study of Schleswig-Holstein
}

\author{
Md. Nasimul Islam Maruf
}

check for updates

Citation: Maruf, M..N.I. A Novel Method for Analyzing Highly Renewable and Sector-Coupled Subnational Energy Systems-Case Study of Schleswig-Holstein. Sustainability 2021, 13, 3852. https:// doi.org/10.3390/su13073852

Academic Editor: Anis Zaman

Received: 4 March 2021

Accepted: 29 March 2021

Published: 31 March 2021

Publisher's Note: MDPI stays neutral with regard to jurisdictional claims in published maps and institutional affiliations.

Copyright: (C) 2021 by the author. Licensee MDPI, Basel, Switzerland. This article is an open access article distributed under the terms and conditions of the Creative Commons Attribution (CC BY) license (https:/ / creativecommons.org/licenses/by/ $4.0 /)$.
Department of Energy and Environmental Management, Auf dem Campus 1, Europa-Universität Flensburg, 24943 Flensburg, Germany; ni.maruf@uni-flensburg.de; Tel.: +49-461-805-3007

Abstract: The energy transition requires an integration of different energy carriers, including electricity, heat, and transport sectors. Energy modeling methods and tools are essential to provide a clear insight into the energy transition. However, the methodologies often overlook the details of small-scale energy systems. The study states an innovative approach to facilitate subnational energy systems with $100 \%$ renewable penetration and sectoral integration. An optimization model, the “Open Sector-coupled Energy Model for Subnational Energy Systems" (OSeEM-SN), was developed under the Open Energy Modeling Framework (Oemof). The model is validated using the case study of Schleswig-Holstein. The study assumes three scenarios representing $25 \%, 50 \%$, and $100 \%$ of the total available biomass potentials. OSeEM-SN reaches feasible solutions without additional offshore wind investment, indicating that it can be reserved for supplying other states' energy demand. The annual investment cost varies between 1.02 and 1.44 bn $€$ /year for the three scenarios. The electricity generation decreases by $17 \%$, indicating that, with high biomass-based combined heat and power plants, the curtailment from other renewable plants can be decreased. Ground source heat pumps dominate the heat mix; however, their installation decreases by $28 \%$ as the biomass penetrates fully into the energy mix. The validation confirms OSeEM-SN as a beneficial tool to examine different scenarios for subnational energy systems.

Keywords: sector coupling; 100\% renewable; subnational energy model; energy transition; open science

\section{Introduction}

To help achieve the $1.5{ }^{\circ} \mathrm{C}$ targets of the Paris Agreement [1], the European Union (EU) needs a transformation of energy system based on the smart integration of renewable energy across different sectors. In the European Green Deal, the European Commission stated plans to integrate renewables, energy efficiency, and other sustainable solutions across sectors to achieve decarbonization at minimum cost [2]. The integration of energy systems is often referred to as "sector coupling" [3]. It indicates the combination of multiple energy sectors, such as electricity, heat, and transport, so that the integrated energy system can achieve the target of overall climate neutrality [4].

Decarbonization of heat and transport sectors depends on state-of-the-art techniques, such as power-to-heat and power-to-gas. These techniques, used in a sector-coupled network, are expected to increase the energy storage capacity and provide additional flexibility to the energy system [5]. The modeling of multiple energy sectors, especially power, heat, and transport, is becoming popular in the newer energy models [6]. In the past decade, many researchers analyzed the feasibility of integrating other sectors, especially the heat sector, in 100\% renewable energy models. These analyses often show that sector coupling decreases the overall system cost; however, the benefits should be further investigated before cross-border transmission in a sector-coupled EU network is implemented [3-6]. 
The North Sea (NS) region can become a pioneer in achieving the European energy transition [7]. The area has enormous offshore wind potential and other renewable sources, such as wave energy, ocean thermal energy conversion, carbon capture and storage, etc. $[7,8]$. It is also possible to strategically transform the region's existing grids and networks to accommodate future sustainable solutions [9]. Collectively, the NS region is in a frontrunner position in the European energy transition [10]. The area can, accordingly, be seen as a representative region covering the critical challenges for change to a sustainable energy system and the consequences for the incumbent system. Data, models, tools, and possible solutions from the NS region will, therefore, constitute essential knowledge and methodologies that can be transferred to other areas in transition [11]. The combined use of different modeling tools and concepts to understand and describe different actors' behavior is essential to provide a coherent picture of the necessary transition process of the energy systems over time and for different spatial levels [10,11].

Modeling methods and tools play a crucial role in providing insights into the energy transition [12]. However, the modeling methodologies often ignore the details of small energy systems. Aggregated models provide more holistic pictures but cannot absorb the regional specifics and often fail to deliver meaningful results at lower spatial scales, including demand behavior. In general, models need not be necessarily larger and more complex; instead, using model collaboration, different approaches and tools are used in conjunction. Aggregated modeling should have proper parameterization and level of detail to capture the main system aspects and interactions. Similarly, disaggregated models should have proper interlinkages with potential developments and system changes across scales $[13,14]$. The linkages between small- and large-scale energy systems need to be addressed better [15]. Developing a methodology for building models with provisions to represent aggregated and disaggregated energy systems will enable users to select the details based on the analysis's objective. The study develops a novel method to facilitate aggregated and disaggregated subnational energy systems with 100\% renewable penetration and sectoral integration. Therefore, the following research question was formulated:

How to develop methodologies for building subnational models of highly renewablebased energy systems within the sector-coupled networks?

The Open Energy Modeling Framework (Oemof) is a useful tool because of its characteristics, such as flexibility, access to collaborative and interdisciplinary modeling, transparency, reliability, open-source, and open data approach to enhance understanding of energy systems and accelerate the energy transition [16-19]. Based on the findings of [20], this study selects Oemof for developing a novel method to answer the research question. This article describes how an hourly optimization model using the Oemof is developed and how to use the model to analyze a subnational energy system. The model is validated using the case study of Schleswig-Holstein (SH) in Germany. Schleswig-Holstein, the northern-most federal state of Germany, is increasingly becoming an energy hub between Germany and the Scandinavian countries, due to its geographic location and the ongoing expansion of onshore wind energy [21,22].

Section 2 briefly compares 16 open model tools, discusses Oemof's usability for developing energy models, and presents Germany's Schleswig-Holstein as a potential region to validate the subnational energy model. Section 3 describes the architecture of the developed model using Oemof. Section 4 describes the application of the model for the case of SH. The input data and the scenarios are presented. Section 5 compares the scenarios and analyzes the results from the SH case study. Section 6 discusses the developed model's usability for a broader context and compares the tool with other Oemof-based applications. Section 7 presents the current limitations of the model and future development plans and summarizes the study.

\section{Background}

Modeling methods and tools play a crucial role in providing the insights mentioned above. A broad range of available state-of-the-art energy models portrays a comprehensible 
picture of the energy transition over different temporal and spatial levels. However, most of these tools are not "open" or "free for educational use," limiting the models' quality, transparency, and credibility. In [20], the author identified 16 "open" tools based on the literature of [23,24], which can be used to model $100 \%$-renewable and sector-coupled energy systems in Europe. The proposed list of tools is presented in Table 1.

\subsection{Modeling Energy Systems Using Oemof}

The background paper by Hilpert et al. [16] describes how Oemof can facilitate open science in energy system modeling. The article discussed the scientific contribution, concept, architecture, implementation, and usage of Oemof. Figure 1 presents a graphical representation of how to describe an arbitrary energy system using Oemof [16].

\section{Energy System}

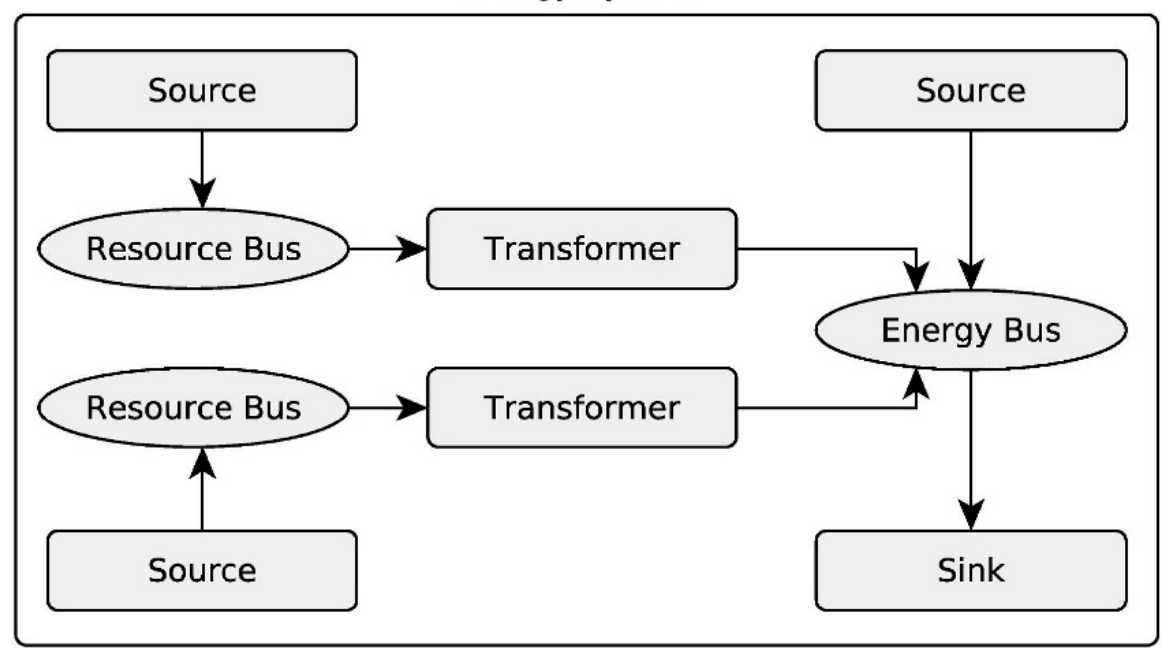

Figure 1. Schematic illustration of an energy system represented as an Oemof network. Reprinted with permission from ref. [16]. Copyright 2021 Elsevier. 
Table 1. The 16 tools for modeling $100 \%$ renewable and sector-coupled energy systems. Adapted from $[20,23,24]$.

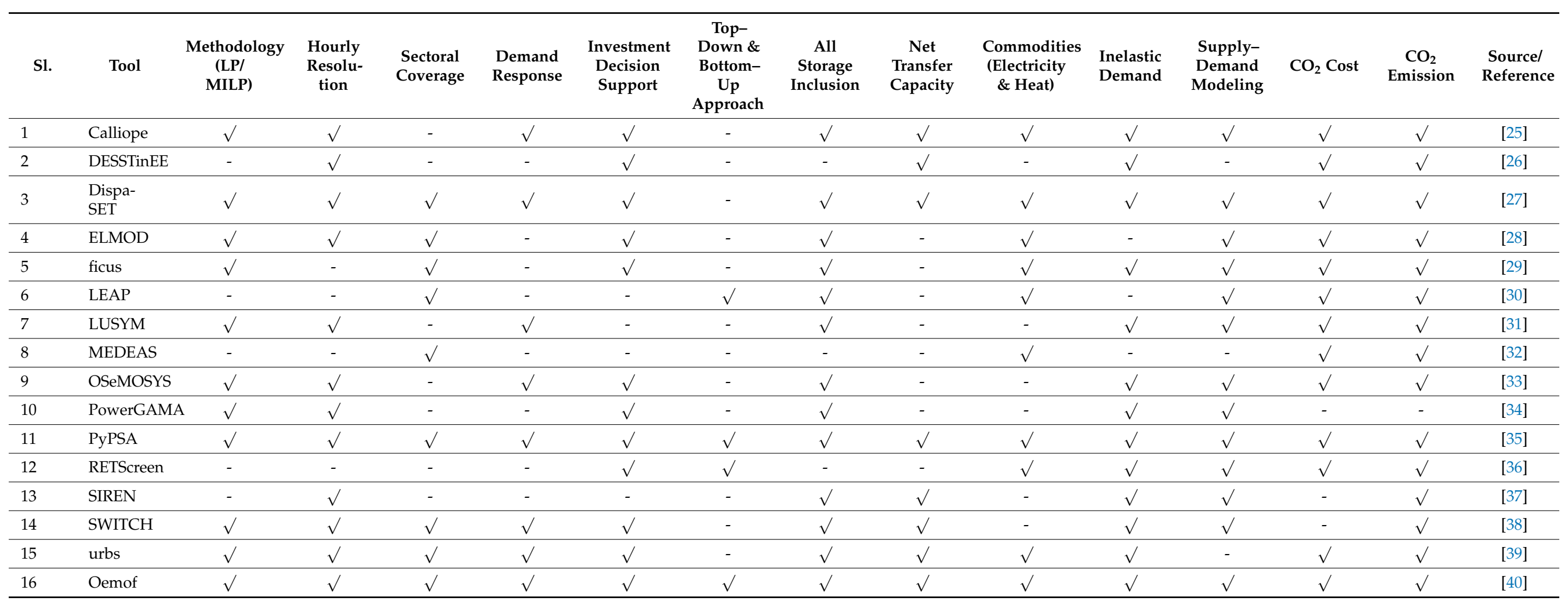


There are two types of nodes in Oemof: components, and buses. Every component has to be connected with one or more buses. The connection between a component and a bus is the flow. The main components of Oemof are Sources, Sinks, and Transformers. The Sources have only outflows. For example, solar photovoltaics (PV), wind turbines, and biomass commodities are modeled as Sources. The Sinks only have inflows. Consumer demands such as electricity or heat loads are modeled as Sinks. Transformers have both inflows and outflows. For example, heat pumps can be modeled as Transformers, which receive electricity inflow and convert it to heat outflow. There are also other components, such as ExtractionTurbineCHP, GenericCHP, Link, GenericStorage, GenericCAES, SinkDSM, etc., which are designed in the Oemof Solph package [41].

There are three ways to create an optimization problem based on Oemof:

1. The energy system describes a graph with flows on its edges by combining necessary components and buses;

2. The basic energy system is adapted by defining additional constraints on top of the aforementioned graph logic; and

3. Custom components are added to a model by subclassing from the core or creating from scratch.

The use cases can be separately or combinedly used in an energy model, allowing maximum flexibility. Oemof provides existing functionalities to build energy models for varying scales. In addition, it enables the combination and adaptation of different energy models to create tools with specific research objectives. It is suggested for readers to go through [16] for further details on the usefulness, usability, and applications of Oemof.

\subsection{Schleswig-Holstein as a Prospective Subnational Region}

For activities and successes in expanding renewable energies, the Schleswig-Holstein achieved first place in the federal state comparison 2019-2020 by the Agentur für Erneuerbare Energien (AEE) [21]. In 2018, electricity generation from renewable energies in SH reached around $150 \%$, which is almost four times Germany's national average of 38\%. SH takes a leading position in the expansion of electricity generation from renewable energies. The share of renewable energies in $\mathrm{SH}$ was almost $15.8 \%$ in the heating sector, slightly above the Germany-wide share of $14.4 \%$. When it comes to the percentage of renewable energies in gross final energy consumption, $\mathrm{SH}^{\prime} \mathrm{s} 36.6 \%$ is well above the national average of $16.5 \%$. SH aims to generate at least 37 terawatt-hours of electricity from renewable energies by the year 2025. Figure 2 shows the individual energy sources' shares in the total final energy supply contribution of renewable energies 2018 [22].

Due to its geographical conditions, $\mathrm{SH}$ is predestined for the use of wind energy. In $\mathrm{SH}$, wind turbines with a nominal output of around 8.2 GW were installed by the end of 2018, which means that electricity from wind energy makes up the largest proportion of SH's electricity supply from renewable energies. SH considers the expansion of wind energy to increase to at least $25 \mathrm{GW}$ by 2030. Biomass represents one of the largest shares $(32.5 \%)$ of renewable energies in SH's supply contribution. Wood, energy crops, straw, and biogas can sustainably generate a significant proportion of the energy requirement. $\mathrm{SH}$ is well-suited for solar systems, as the increased amount of wind between the seas provides natural cooling. The potential of geothermal energy in $\mathrm{SH}$ is particularly suitable for space heating and electricity production. Due to the lack of landscape conditions, water traditionally plays a subordinate role as an energy source in Schleswig-Holstein. Since geothermal energy does not depend on the weather or the course of the day, it is ideal for covering the base and medium loads in the heating and electricity markets [21,22].

The geological subsurface is suitable for storing considerable amounts of energy carriers (e.g., hydrogen, synthetic methane), potential energy, or thermal energy. In theory, porous geological layers and cavities in the subsurface can be used for storage. The latest energy models to analyze the SH energy system should consider the compressed air energy storage capacities in geological formations. Due to the problem-free storage and the diverse and flexible application possibilities, hydrogen is a perfect link in the sector coupling. 
Hydrogen can make a significant contribution to the decarbonization of these areas of application and comply with the climate policy $\mathrm{CO}_{2}$ reduction targets by 2050 [22].

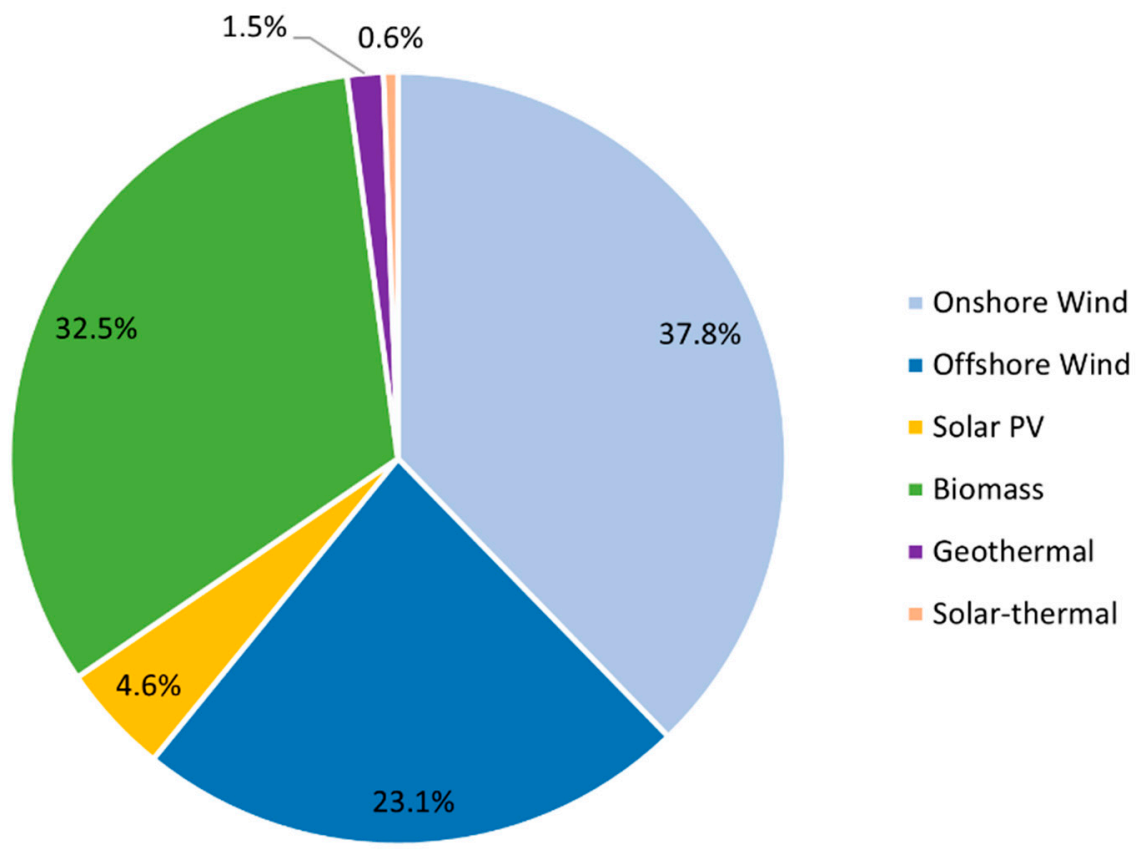

Figure 2. Shares of the renewable sources in the total renewable energy supply in Schleswig-Holstein (SH) (2018).

Two points are clear from the literature review: First, Oemof can be used to develop methodologies for building energy models ranging of varying geographical and temporal scopes for highly renewable energy integrated energy systems with interlinked sectors. Second, Schleswig-Holstein is an ideal subnational region to validate the developed energy model for its prospects in expanding renewable energies across all sectors. Therefore, the study used Oemof to build an open sector-coupled subnational energy model and validated it for SH's case.

\section{Model Architecture}

\subsection{Elements and Objective Function}

The study developed a unique hourly optimization tool using a hybrid approach. The technological capacities are exogenously set, and the investment capacities are endogenously resolved. Technical limits set the boundary of the system so that the solutions are realistic. The subnational model, "Open Sector-coupled Energy Model for Subnational Energy Systems" (OSeEM-SN), was created using Oemof Tabular [42]. Figure 3 illustrates the OSeEM-SN energy model.

The model presents $\mathrm{SH}$ as a self-sufficient energy system, where the demands are met using its renewable resources. In the real case, other energy systems are connected with the SH system; for example, the neighboring region's electricity bus will be connected with SH's electricity bus using a transmission line (transshipment approach), which uses the Oemof class Link. For visualizing such energy systems, the readers are suggested to look into [43], where the author connected two energy systems using Link. The model also does not consider industrial process heating because of limited data availability and model complexity of high-temperature technologies. The nodes (i.e., components and buses) of the OSeEM-SN model, according to the Oemof Classes, are presented in Table 2. 


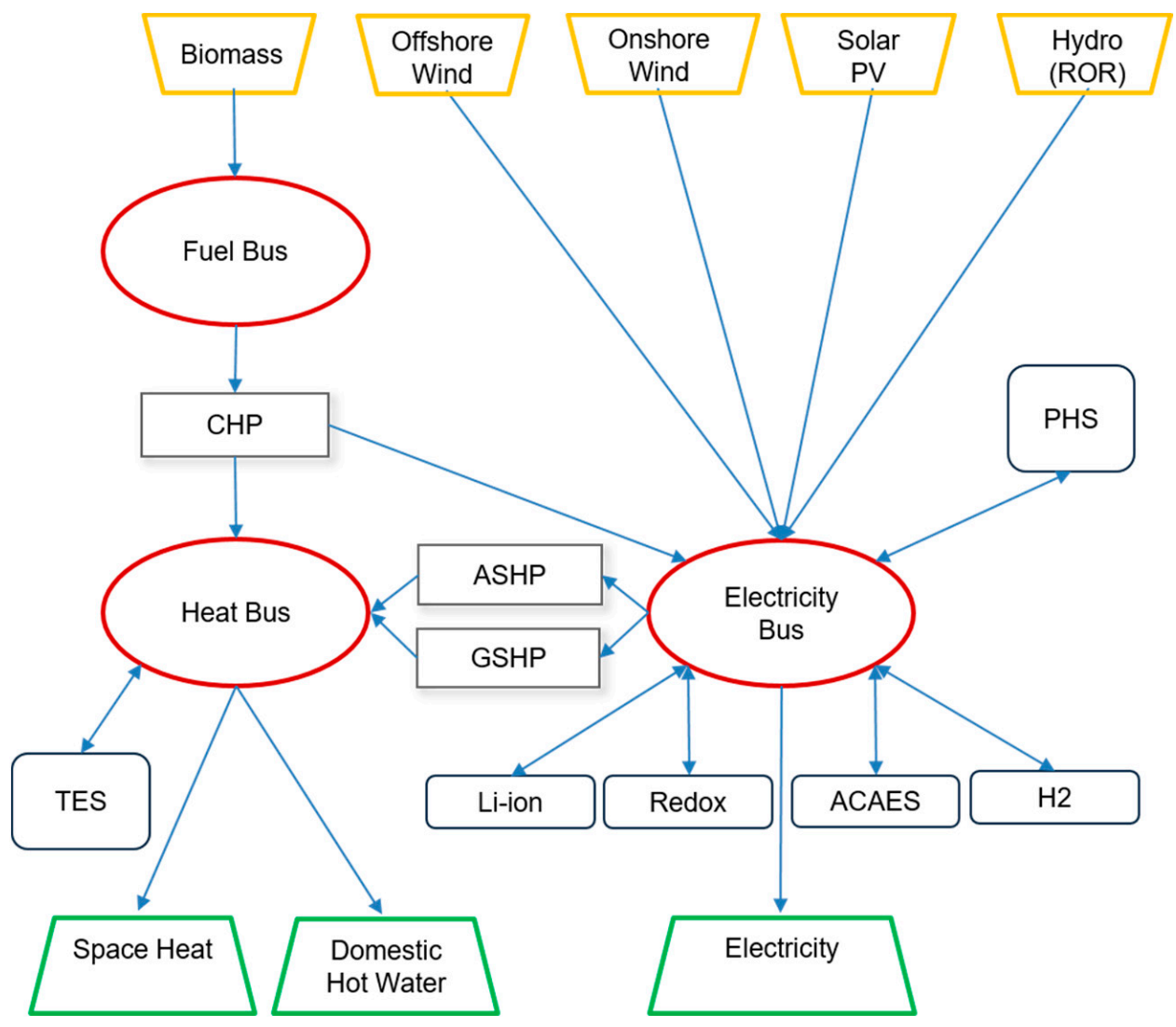

Figure 3. Simplified block diagram of the Open Sector-coupled Energy Model for Subnational Energy Systems (OSeEM-SN) model.

Table 2. List of all components and buses of the OSeEM-SN model.

\begin{tabular}{|c|c|c|}
\hline Oemof Class & Nodes & Remarks \\
\hline Bus & $\begin{array}{l}\text { Electric Bus } \\
\text { Heat Bus } \\
\text { Fuel Bus }\end{array}$ & Represents grid or network without losses. \\
\hline Sink & $\begin{array}{l}\text { Electricity } \\
\text { Space Heat } \\
\text { Domestic Hot Water (DHW) }\end{array}$ & $\begin{array}{l}\text { Represents the electricity and building heat } \\
\text { demands in the energy system. }\end{array}$ \\
\hline \multirow[t]{2}{*}{ Source } & $\begin{array}{l}\text { Offshore Wind } \\
\text { Onshore Wind } \\
\text { Solar PV } \\
\text { Hydro Run-of-the-river (ROR) }\end{array}$ & $\begin{array}{l}\text { Represents the volatile generators of the energy } \\
\text { system. }\end{array}$ \\
\hline & Biomass & $\begin{array}{l}\text { Represents the biomass commodities which are fed } \\
\text { into the CHP plants. }\end{array}$ \\
\hline ExtractionTurbine CHP & Combined Heat and Power (CHP) & $\begin{array}{l}\text { Represents the heat generators of the energy system. } \\
\text { The OSeEM-SN model uses extraction turbines and } \\
\text { uses only biomass as the fuel. }\end{array}$ \\
\hline Transformer & $\begin{array}{l}\text { Air Source Heat Pump (ASHP) } \\
\text { Ground Source Heat Pump (GSHP) }\end{array}$ & Complements CHP for meeting heating demands. \\
\hline
\end{tabular}


Table 2. Cont.

\begin{tabular}{llr}
\hline \multicolumn{1}{c}{ Oemof Class } & \multicolumn{1}{c}{ Nodes } & \multicolumn{1}{c}{ Remarks } \\
\hline \multirow{2}{*}{ GenericStorage } & $\begin{array}{l}\text { Li-ion (Li-ion) } \\
\text { Vanadium Redox Flow (Redox) }\end{array}$ & Represents batteries. \\
\cline { 2 - 3 } & $\begin{array}{l}\text { Adiabatic Compressed Air Energy } \\
\text { Storage (ACAES) } \\
\text { Hydrogen }\left(\mathrm{H}_{2}\right)\end{array}$ & $\begin{array}{c}\text { Simplified model as Generic Storage. Presents } \\
\text { electricity storage. }\end{array}$ \\
\cline { 2 - 3 } & Pumped Hydro Storage (PHS) & $\begin{array}{c}\text { Storage units with constant inflow and possible } \\
\text { spillage. The storage capacity is not expandable. }\end{array}$ \\
\cline { 2 - 3 } & Thermal Energy Storage (TES) & $\begin{array}{r}\text { Simplified model as Generic Storage. Presents heat } \\
\text { storage in sensible hot water tanks. }\end{array}$ \\
\hline
\end{tabular}

The OSeEM-SN model follows the formulation described by Hilpert [44]. The model limits the volatile generators, biomass commodities, and storage capacities by putting maximum limits. However, the limit for using heat pumps depends on the electricity availability. OSeEM-SN uses a perfect foresight approach, indicating the weather and renewable data are provided in advance. Detailed mathematical formulations for the OSeEM-SN model follow the modeling equations presented by Maruf [43]. The model optimizes the operating and investment costs of all the volatile generators, combined heat and power (CHP), heat pumps, and storages. The endogenous variables are presented using $x$, and the exogenous parameters are presented using $c$, as listed in Table 3.

Table 3. Variables and parameters for cost optimization of OSeEM-SN.

\begin{tabular}{|c|c|c|}
\hline Variables/Parameters & Description & Technology \\
\hline$x_{v}^{\text {flow }}$ & Flow of volatile generator unit $v$ & \multirow{4}{*}{$\begin{array}{c}\text { Offshore Wind } \\
\text { Onshore Wind } \\
\text { Solar PV } \\
\text { Hydro ROR }\end{array}$} \\
\hline$x_{v}^{\text {capacity }}$ & Capacity of volatile generator unit $v$ & \\
\hline$c_{v}^{\text {marginal_cost }}$ & Marginal cost ${ }^{1}$ of volatile generator unit $v$ [43] & \\
\hline$c_{v}^{\text {capacity_cost }}$ & Capacity cost ${ }^{2}$ of volatile generator unit $v$ [43] & \\
\hline$x_{\text {chp }}^{\text {flow }}$ & Flow of CHP unit chp & \multirow{4}{*}{$\mathrm{CHP}$} \\
\hline$x_{\text {chp }}^{\text {capacity }}$ & Capacity of CHP unit chp & \\
\hline$c_{\text {chp }}^{\text {marginal_cost }}$ & Marginal cost of CHP unit chp & \\
\hline$c_{\text {chp }}^{\text {capacity_cost }}$ & Capacity cost of CHP unit chp & \\
\hline$x_{h}^{\text {flow }}$ & Flow of heat pump unit $h$ & \multirow{4}{*}{$\begin{array}{l}\text { ASHP } \\
\text { GSHP }\end{array}$} \\
\hline$x_{h}^{\text {capacity }}$ & Capacity of heat pump unit $h$ & \\
\hline$c_{h}^{\text {marginal_cost }}$ & Marginal cost of heat pump unit $h$ & \\
\hline$c_{h}^{\text {capacity_cost }}$ & Capacity cost of heat pump unit $h$ & \\
\hline$x_{s}^{\text {flow }}$ & Flow of storage unit $s$ & \multirow{6}{*}{$\begin{array}{c}\text { Li-ion } \\
\text { Redox } \\
\text { ACAES } \\
\mathrm{H}_{2} \\
\text { PHS (No Investment) } \\
\text { TES }\end{array}$} \\
\hline$x_{s}^{\text {capacity }}$ & Capacity (power) of storage unit $s$ & \\
\hline$x_{s}^{\text {storage_capacity }}$ & Storage capacity (energy) of storage unit $s$ & \\
\hline$c_{S}^{\text {marginal_cost }}$ & Marginal cost of storage unit $s$ & \\
\hline$c_{S}^{c a p a c i t y \_c o s t}$ & Capacity cost (power) of storage unit $s$ & \\
\hline$c_{S}^{\text {storage_capacity_cost }}$ & Storage capacity cost (energy) of storage unit $s$ & \\
\hline
\end{tabular}


The objective function of OSeEM-SN is created from all instantiated objects, which use all operating costs and investment costs arguments:

$$
\begin{aligned}
& \min : \sum_{v, t} \overbrace{x_{v}^{f l o w}(t) \cdot c_{v}^{\text {marginal_cost }}}^{\text {operating_cost Volatile Generator }}+\sum_{v} \overbrace{x_{v}^{\text {capacity }} \cdot c_{v}^{\text {capacity_cost }}}^{\text {investment_cost Volatile Generator }}+ \\
& \sum_{\begin{array}{c}
\text { chp }, t \\
\text { operating_cost Heat Pump }
\end{array}} \overbrace{x_{\text {fhp }}^{\text {flow }}(t) \cdot c_{c h p}^{\text {marginal_cost }}}^{\text {operating_cost CHP }}+\sum_{\sum_{\text {chp } p} \overbrace{x_{\text {chp }}^{\text {capacity }} \cdot c_{\text {chp }}^{\text {capacity_cost }}}^{\text {investment cost_CHP }}}^{\text {investment_cost Heat Pump }} \\
& \sum_{h, t} \overbrace{x_{h}^{\text {flow }}(t) \cdot c_{h}^{\text {marginal_cost }}}^{\text {operating_cost Heat Pump }}+\sum_{h} \overbrace{x_{h}^{\text {capacity }} \cdot c_{h}^{\text {capacity_cost }}}^{\text {investment_cost Heat Pump }}+ \\
& \sum_{s, t} \overbrace{x_{s}^{f l o w}(t) \cdot c_{S}^{\text {marginal_cost }}}^{\text {operating_cost Storage }}+ \\
& \sum_{S} \overbrace{x_{S}^{\text {capacity }} \cdot c_{S}^{\text {capacity_cost }}+x_{S}^{\text {storage_capacity }} \cdot c_{S}^{\text {storage_capacity_cost }}}^{\text {investment_cost Storage }}
\end{aligned}
$$

\subsection{Development Methodology}

OSeEM-SN considers the existing capacities of the volatile generators and pumped hydro storage (PHS). The model also assumes that the current biomass and biogas capacities are converted to CHPs. The maximum potentials of the resources limit the investment capacities of additional volatile generators and CHPs. The storage capacities are expandable to their utmost limits, except PHS, where no further capacity expansion is possible. Heat pump expansion depends upon the availability of power from renewable electricity resources. The model also uses cost and demand data as inputs of the model. After investment and dispatch optimization, the model outputs such as investment capacities can be obtained. Details of the model input and output are presented in Figure 4.

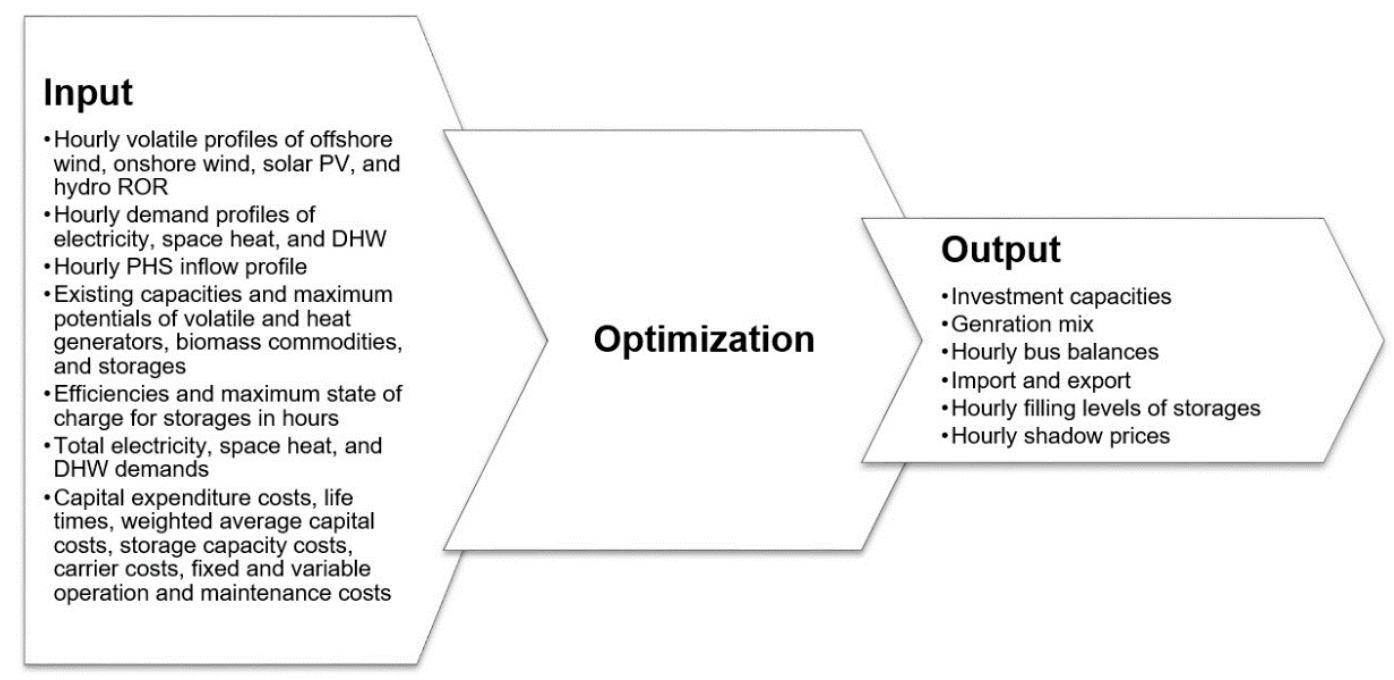

Figure 4. OSeEM-SN Input and Output.

The OSeEM-SN model was developed using a Python Script, Oemof Solph, Oemof Tabular, and tabular csv data files. The development methodology steps for OSeEM-SN are stated below:

1. Importing necessary data packages (Python Script)

2. Setting up the input datapath (Python Script)

3. Setting up the result directory (Python Script) 


\section{4. $\quad$ Reading input data (Python Script)}

5. Creating the energy system (Oemof Solph)

6. Creating the buses (Oemof Solph)

7. Adding buses to the energy system (Oemof Solph)

8. Adding components to the energy system (Oemof Tabular)

9. Reading demand data (Oemof Tabular)

10. Creating the model (Oemof Solph)

11. Solve the optimization problem (Oemof Solph)

12. Postprocessing of results (Oemof Tabular)

13. Writing results (Oemof Tabular)

14. Plotting results (Oemof Tabular)

Data preparation is an essential step of the model development process, where the data are normalized and scaled for use as the inputs of OSeEM-SN. For different scenarios, the input data are varied in the data handling stage.

\section{Model Validation: Case of Schleswig-Holstein}

\subsection{Hourly Renewable Profiles and Demand Data}

The OSeEM-SN model is validated using historical data for a full year. According to [45], data from 2011 are used for analyzing 2050 scenarios, except for hydro data, which uses 2016 data. Table 4 shows the hourly input data sources used for validating the OSeEM-SN model.

Table 4. Hourly input data sources for the OSeEM-SN model.

\begin{tabular}{llc}
\hline \multicolumn{1}{c}{ Data } & \multicolumn{1}{c}{ Source } & Remarks \\
\hline $\begin{array}{l}\text { Wind profiles } \\
\text { Solar PV profiles }\end{array}$ & Renewables Ninja project [46] & $\begin{array}{c}\text { Based on the MERRA-2 } \\
\text { dataset. }\end{array}$ \\
\hline $\begin{array}{l}\text { Hydro ROR inflow } \\
\text { PHS scaled inflow }\end{array}$ & Dispa-SET project [47] & - \\
\hline Electricity demand & OPSD project [48] & $\begin{array}{c}\text { Based on the ENTSO-e } \\
\text { statistical database [49]. }\end{array}$ \\
\hline Space heat demand & OPSD project [48] & $\begin{array}{c}\text { Based on the When2Heat } \\
\text { dataset [50] }\end{array}$ \\
\hline
\end{tabular}

The onshore wind profile is obtained from the MERRA-2, current fleet dataset for the NUTS-2 region (SH: DEF0). The offshore wind profile represents the offshore profile of Germany based on the MERRA-2 database. The solar PV profile is also obtained for $\mathrm{SH}$ (NUTS2, DEF0). The hydro run-of-the-river (ROR) and PHS scaled inflows are obtained from Dispa-SET's 2016 data. The inflows are defined as the contribution of exogenous sources to the level (or state of charge) or the reservoir. Scaled inflows are normalized values of the inflow concerning the nominal power of the storage unit. The PHS inflows are scaled down to match SH's inflow profile (in MWh). Germany's demand data (electricity, space heat, domestic hot water (DHW)) are downscaled based on population to represent SH's hourly demand profiles. The wind, solar, and hydro normalized profiles do not change in the scenarios and can be visualized as shown in Figure 5.

Figure 6 shows the normalized demand profiles of $\mathrm{SH}$ in 2050. The total electricity demand for SH in 2050, based on the representative year, is $18.6 \mathrm{TWh}_{\mathrm{el}}$. Total space heat demand is $18.6 \mathrm{TWh}_{\mathrm{th}}$, and the DHW demand is $4 \mathrm{TWh}_{\mathrm{th}}$. The amount of available biomass is calculated from the Hotmaps project [51]. The study assumes that the existing biomass and biogas power plants are converted to CHP plants by 2050. CHP's electrical and thermal efficiencies are assumed to be $45 \%$, and the condensing efficiency is assumed to be $50 \%$. The coefficient of performance (COP) of the air source heat pump (ASHP) and ground source heat pump (GSHP) are assumed to be 2.3 and 3.9, respectively [52]. 


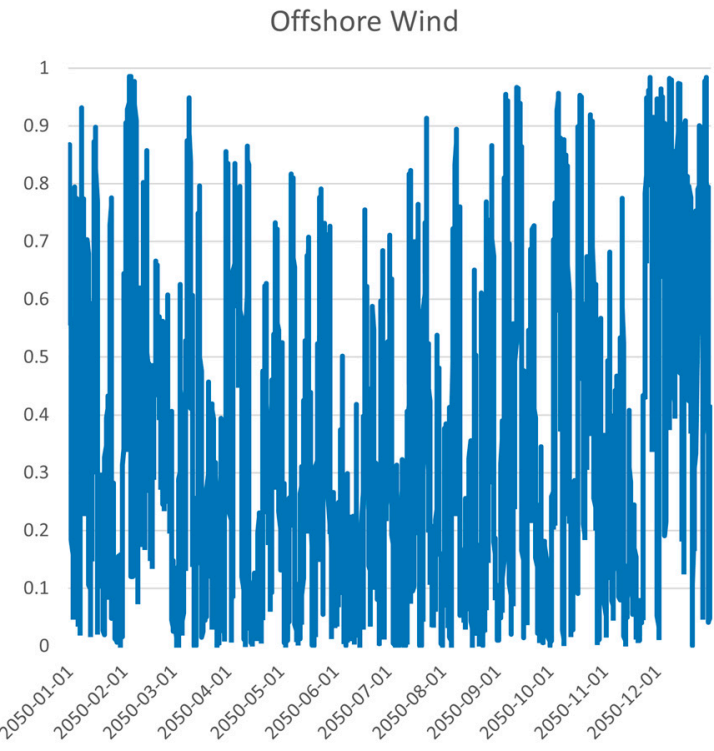

(a)

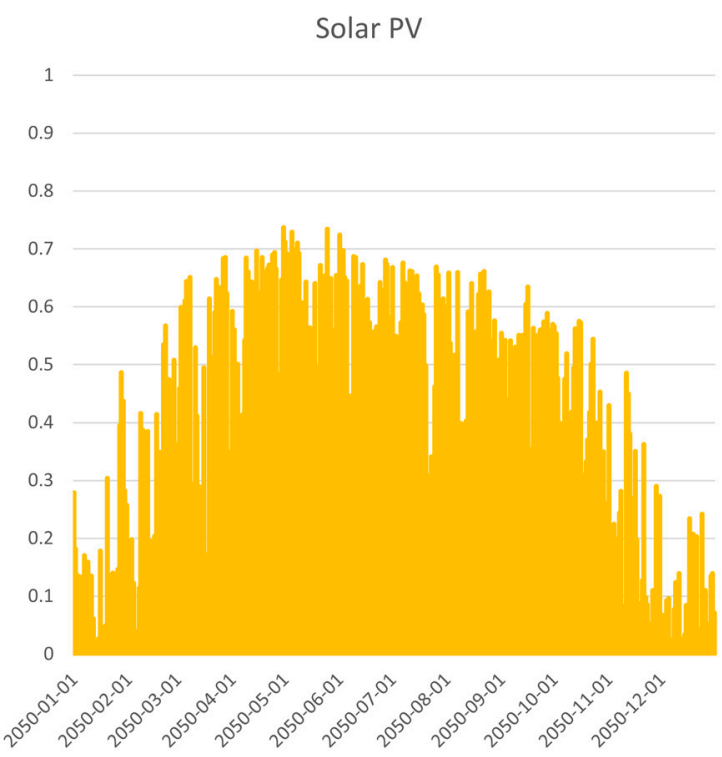

(c)
Onshore Wind

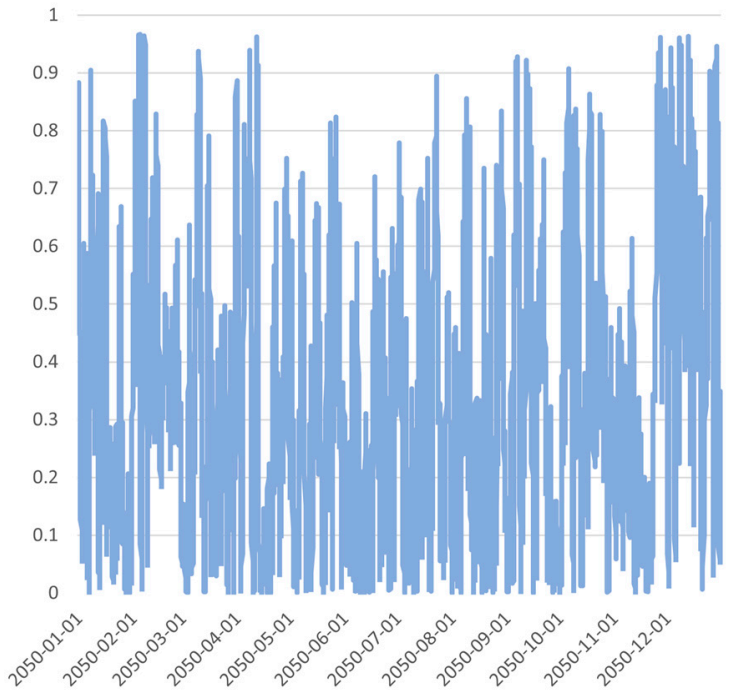

(b)

Hydro ROR

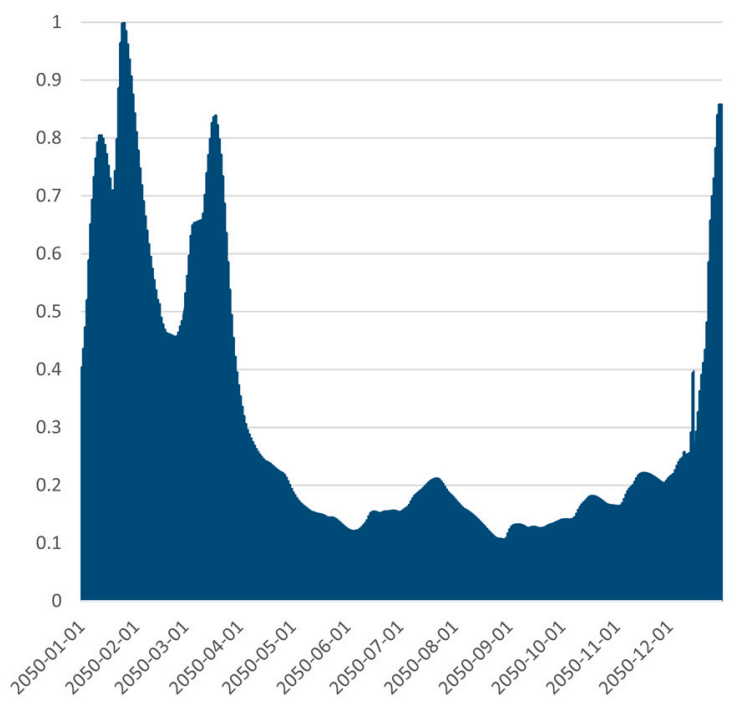

(d)

Figure 5. Normalized input profiles of volatile generators of OSeEM-SN model, (a) offshore wind, (b) onshore wind, (c) solar photovoltaics (PV), and (d) hydro run-of-the-river (ROR).

\subsection{Capacity and Available Potential}

The existing capacities and available potentials for the volatile generators and the storage investments are taken from different sources, namely the Hotmaps project [51], ANGUS II project [52], Deutsche WindGuard [53], AEE [54], and LIMES-EU project [55], as listed in Table 5. The available potentials are calculated from the maximum potentials and the existing capacities. The Li-ion, vanadium redox flow (Redox), and hydrogen $\left(\mathrm{H}_{2}\right)$ potentials are assumed to be $5 \%$ of Germany's available potentials, as stated in the project databases. The adiabatic compressed air energy storage (ACAES) potential is assumed to be $50 \%$ of Germany's total potential because of its availability in only Northern Germany. 


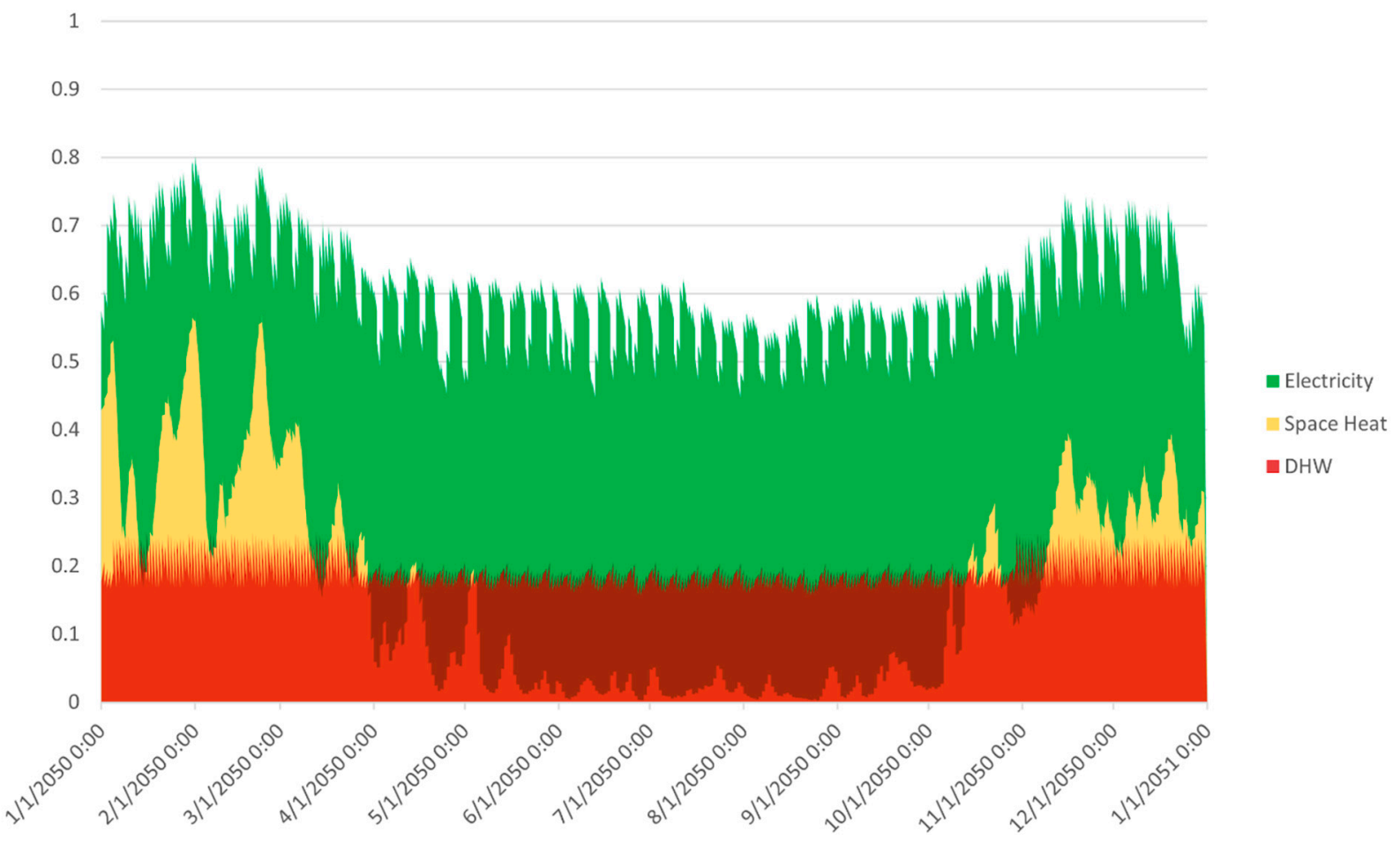

Figure 6. Normalized demand profiles of SH in 2050.

Table 5. Capacity and available potential for volatile generators and storage in SH in 2050.

\begin{tabular}{|c|c|c|}
\hline Technology & Existing Capacity & Available Potential \\
\hline Onshore Wind $\left[\mathrm{GW}_{\mathrm{el}}\right]$ & 7 [53] & 1.9 [54] \\
\hline Offshore Wind $\left[\mathrm{GW}_{\mathrm{el}}\right]$ & $1.7[53]$ & $25.2^{1}[55]$ \\
\hline Solar PV $\left[\mathrm{GW}_{\mathrm{el}}\right]$ & $1.6[54]$ & $6.7[54]$ \\
\hline Hydro ROR $\left[\mathrm{MW}_{\mathrm{el}}\right]$ & $2[54]$ & $4[54]$ \\
\hline Biomass \& Biogas & 1 GWh [54] & 21.8 PJ [51] \\
\hline Li-ion $\left[\mathrm{MW}_{\mathrm{el}}\right]$ & - & $782.5[52]$ \\
\hline Redox $\left[\mathrm{MW}_{\mathrm{el}}\right]$ & - & $46.5[52]$ \\
\hline $\mathrm{H}_{2}\left[\mathrm{MW}_{\mathrm{el}}\right]$ & - & $505[52]$ \\
\hline ACAES $\left[\mathrm{MW}_{\mathrm{el}}\right]$ & - & $1715.5[52]$ \\
\hline PHS $\left[\mathrm{MW}_{\mathrm{el}}\right]$ & $120[56]$ & - \\
\hline TES $\left[\mathrm{MW}_{\mathrm{th}}\right]$ & - & $1000^{2}$ \\
\hline
\end{tabular}

1 The maximum offshore wind potential, according to the LIMES-EU project, is $83.6 \mathrm{GW}_{\mathrm{el}}$. The available potential of $\mathrm{SH}$ assumes the equal distribution of remaining capacities in the three northern states of Germany. ${ }^{2}$ Own assumption.

\subsection{Cost Data}

Table 6 presents the cost data taken from various resources as described in [43].

\subsection{Other Input Data}

The loss rates are $1 \%$ for PHS and $1.4 \%$ for thermal energy storage (TES) [52]. Hydro ROR efficiency is $90 \%$ [52]. The roundtrip efficiencies are $92 \%, 80 \%, 46 \%, 75 \%, 73 \%$, and $81 \%$ for Li-ion, Redox, $\mathrm{H}_{2}, \mathrm{PHS}$, ACAES, and TES, respectively [52]. The maximum state of charge capacity in terms of hours at full output capacity is $6.5 \mathrm{~h}, 3.3 \mathrm{~h}, 168 \mathrm{~h}, 8 \mathrm{~h}, 7 \mathrm{~h}$, and $72 \mathrm{~h}$ for Li-ion, Redox, $\mathrm{H}_{2}, \mathrm{PHS}, \mathrm{ACAES}$, and TES, respectively [52]. Land limitation for onshore wind is $4 \mathrm{MW} / \mathrm{km}^{2}$, and offshore wind is $6 \mathrm{MW} / \mathrm{km}^{2}$ [55]. The solar PV installations consider the protection of nature reserves and restricted zones. 
Table 6. Cost data for OSeEM-SN Model [43].

\begin{tabular}{|c|c|c|c|c|c|c|c|c|c|c|c|c|c|}
\hline Technology & $\begin{array}{l}\text { Onshore } \\
\text { Wind }\end{array}$ & $\begin{array}{l}\text { Offshore } \\
\text { Wind }\end{array}$ & PV & ROR & Biomass & Li-ion & $\mathbf{H}_{2}$ & Redox & PHS & ASHP & GSHP & ACAES & TES \\
\hline $\begin{array}{c}\text { Capex } \\
(€ / \mathrm{kW})\end{array}$ & 1075 & 2093 & 425 & 3000 & 1951 & 35 & 1000 & 600 & 2000 & 1050 & 1400 & 750 & 0 \\
\hline $\begin{array}{l}\text { Lifetime } \\
\text { (Years) }\end{array}$ & 25 & 25 & 25 & 50 & 30 & 20 & 22.5 & 25 & 50 & 20 & 20 & 30 & 20 \\
\hline WACC & 0.025 & 0.048 & 0.021 & 0.05 & 0.05 & 0.05 & 0.05 & 0.05 & 0.05 & 0.05 & 0.05 & 0.05 & 0.05 \\
\hline $\begin{array}{l}\text { VOM Cost } \\
(€ / M W h)\end{array}$ & 0 & 0 & 0 & 0 & 11.3 & 1 & 1 & 1 & 0 & 0 & 0 & 1 & 0 \\
\hline $\begin{array}{l}\text { FOM Cost } \\
(€ / \mathrm{kWh}) \\
\text { Storage }\end{array}$ & 35 & 80 & 25 & 60 & 100 & 10 & 10 & 10 & 20 & 36.75 & 49 & 10 & 0.38 \\
\hline $\begin{array}{c}\text { Capacity Cost } \\
(€ / \mathrm{kWh})\end{array}$ & - & - & - & - & - & 187 & 0.2 & 70 & - & - & - & 40 & 38 \\
\hline $\begin{array}{c}\text { Carrier Cost } \\
(€ / \mathrm{MWh})\end{array}$ & - & - & - & - & 34.89 & - & - & - & - & - & - & - & - \\
\hline
\end{tabular}

\subsection{Scenarios}

The study assumes three scenarios for validating the OSeEM-SN model for SchleswigHolstein: BM-25, BM-50, and BM-100. The scenarios represent $25 \%, 50 \%$, and $100 \%$ of the total available biomass potentials, respectively. The study aims to investigate how the results change upon varying one parameter of the model. However, the model does not account for all the parametric variations for the input data; rather, it focuses on the model's usability to create different scenarios and examine different possible pathways.

\section{Results}

\subsection{Supply-Demand Matching}

The OSeEM-SN model reached feasible solutions for all three scenario assumptions. Figure 7 shows the supply-demand matching of electricity and heat demands for the three different scenarios over the year 2050 .

The energy generation from onshore wind in BM-25 is $26.6 \mathrm{TWh}_{\mathrm{el}}$, which drops to 20.9 $\mathrm{TWh}_{\mathrm{el}}$ in the BM-50 and BM-100 scenarios. Similarly, solar PV generation drops from 8.7 $\mathrm{TWh}_{\mathrm{el}}$ in the BM-25 scenario to $6.8 \mathrm{TWh}_{\mathrm{el}}$ in the BM-50 scenario and $4.6 \mathrm{TWh}_{\mathrm{el}}$ in the BM-100 scenario. Offshore wind generation remains the same, $5.5 \mathrm{TWh}_{\mathrm{el}}$, in all three scenarios. The CHP generation for electricity and heat increases with increasing biomass availability in the scenarios, from 1.5 TWh in the BM-25 to 3 TWh in the BM-50 scenario and 3.8 TWh in the BM-100 scenario. In contrast, heat pump (GSHP and ASHP) generation reduces from 21.5 $\mathrm{TWh}_{\text {th }}$ in BM-25 to 18.9 $\mathrm{TWh}_{\text {th }}$ in the $\mathrm{BM}-100$ scenario. Therefore, it is obvious from the scenarios that, with increasing biomass penetration in the energy mix, the CHP plant capacities are expanded, increasing electricity and heat generation. This, in turn, reduces the expansion of other power plants and heat pumps to meet the demands.

\subsection{Scenario Comparison}

\subsubsection{Capacity Expansion}

According to the optimization from OSeEM-SN, the required investment of different technologies can be obtained. Table 7 compares the required investments on top of the existing capacities of Table 5 for the three scenarios. 


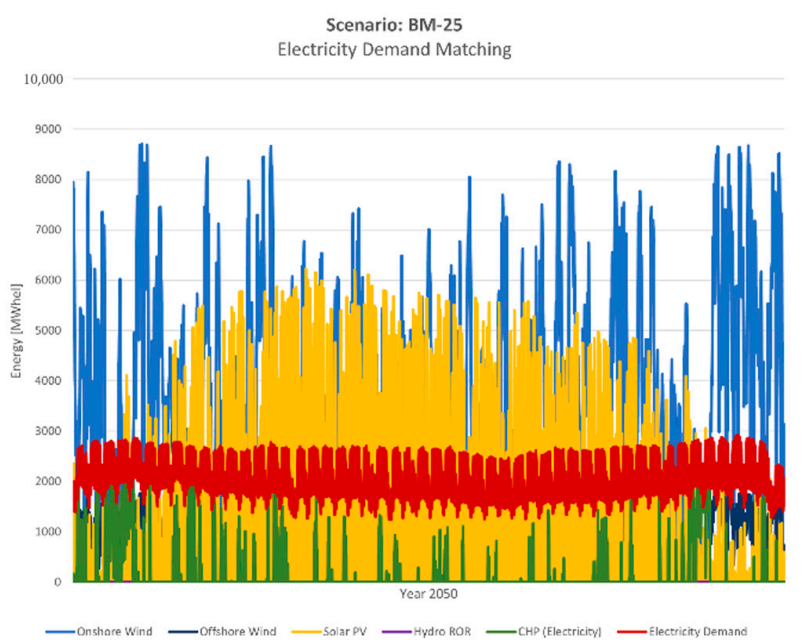

(a)

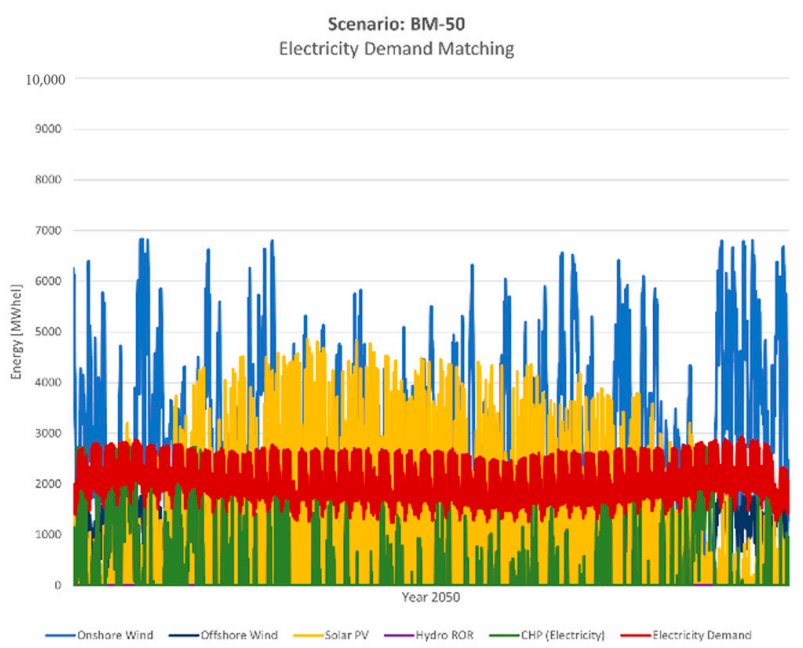

(c)

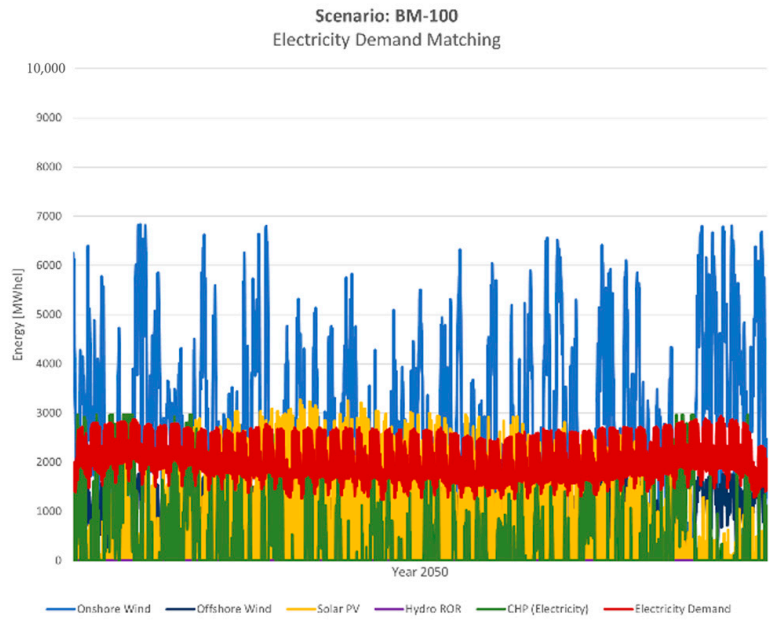

(e)

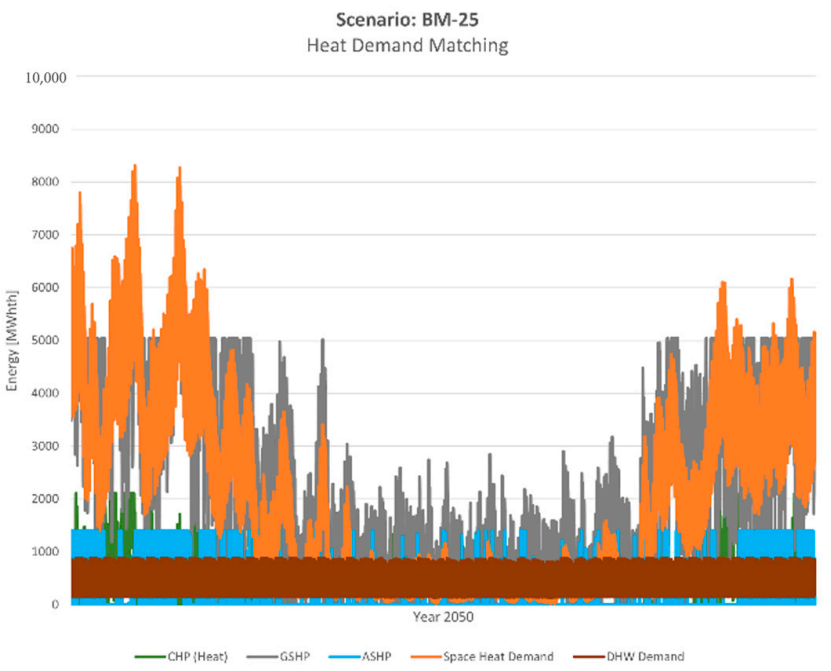

(b)

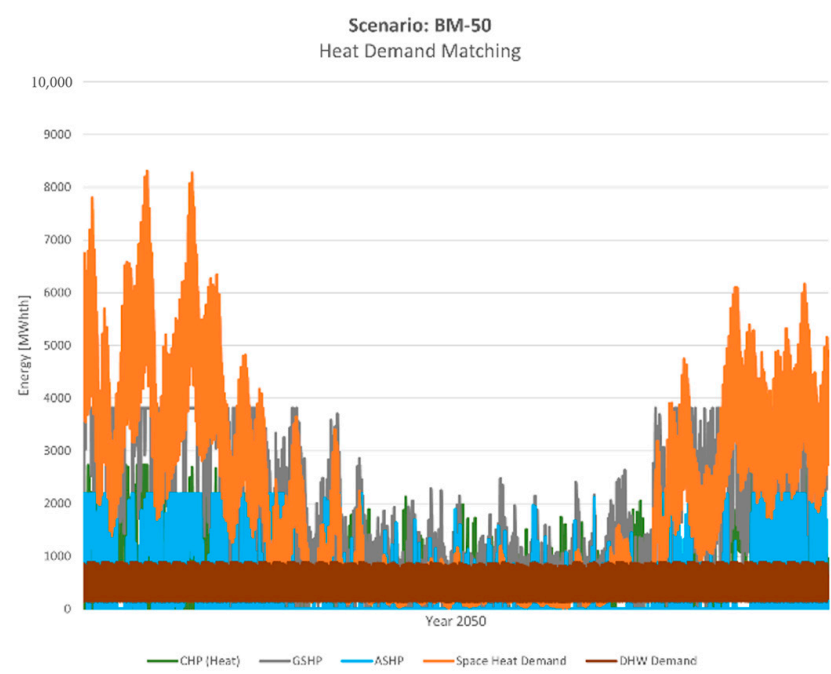

(d)

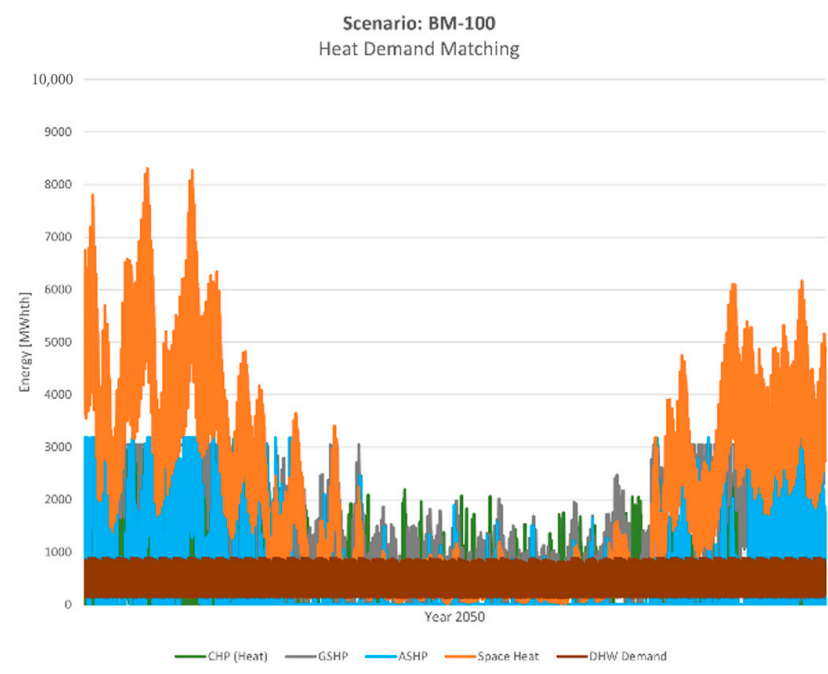

(f)

Figure 7. Supply-demand matching for the three scenarios over the year 2050. (a) BM-25 electricity demand matching; (b) BM-25 heat demand matching; (c) BM-50 electricity demand matching; (d) BM-50 heat demand matching; (e) BM-100 electricity demand matching; (f) BM-100 heat demand matching. 
Table 7. Comparison of capacity expansion for three scenarios.

\begin{tabular}{|c|c|c|c|}
\hline \multirow{2}{*}{ Technology } & \multicolumn{3}{|c|}{ Scenario-Wise Investments } \\
\hline & BM-25 & BM-50 & BM-100 \\
\hline Onshore Wind [GW $\left.\mathrm{Gl}_{\mathrm{el}}\right]$ & 1.9 & 0 & 0 \\
\hline Offshore Wind $\left[\mathrm{GW}_{\mathrm{el}}\right]$ & 0 & 0 & 0 \\
\hline Solar PV $\left[\mathrm{GW}_{\mathrm{el}}\right]$ & 6.7 & 4.9 & 2.7 \\
\hline Hydro ROR $\left[\mathrm{MW}_{\mathrm{el}}\right]$ & 4 & 4 & 4 \\
\hline $\mathrm{CHP}[\mathrm{GW}]$ & 1 & 1.6 & 1.9 \\
\hline GSHP $\left[\mathrm{GW}_{\mathrm{th}}\right]$ & 5 & 3.8 & 3 \\
\hline ASHP $\left[G_{\text {th }}\right]$ & 1.3 & 2.1 & 3.1 \\
\hline Li-ion $\left[\mathrm{MW}_{\mathrm{el}}\right]$ & 782.5 & 782.5 & 782.5 \\
\hline Redox $\left[\mathrm{MW}_{\mathrm{el}}\right]$ & 46.5 & 46.5 & 46.5 \\
\hline $\mathrm{H}_{2}\left[\mathrm{MW}_{\mathrm{el}}\right]$ & 397 & 0 & 0 \\
\hline ACAES $\left[\mathrm{MW}_{\mathrm{el}}\right]$ & 357.1 & 357.1 & 357.1 \\
\hline TES $\left[\mathrm{MW}_{\mathrm{th}}\right]$ & 1000 & 460.2 & 0 \\
\hline
\end{tabular}

The results show no need for additional investment in offshore wind plants to meet SH's energy demand. As a result, the offshore capacities can be reserved for supplying other states' energy demand, especially those in Southern Germany. CHP investment rises because of the higher availability of biomass over the three scenarios and the high overall efficiency due to the combined production of electricity and heat. This impacts the investment in onshore wind and solar PV capacities and reduces investments in volatile generators. GSHP investment also decreases with increasing CHPs; however, ASHP investment increases to complement the heating demand. For storage, Li-ion, Redox, and ACAES are used to their maximum investment capacities for all three scenarios. Hydrogen storage is used only in the BM-25 scenario, indicating its use only in low biomass availability cases. The need for TES storage decreases over the scenarios with more biomass availability. Therefore, with limited biomass, it is possible to meet the heat demand with a heat storage option.

\subsubsection{Investment Cost}

The study calculates the annual investment cost (AIV) by multiplying the annuity with the model's optimized capacity, as shown by Equation (2). The annuity calculation is shown in Equation (3), which considers the capital expenditure (Capex), weighted average cost of capital (WACC), and the lifetime (n). The total investment cost (TIV) is obtained by multiplying the Capex and the model's optimized capacity, as shown by Equation (4). In the case of storage, the investment cost considers both power and energy costs.

$$
\begin{aligned}
c^{\text {AIV }} & =c^{\text {Annuity }} \cdot c^{\text {optimized_capacity }} \\
c^{\text {Annuity }} & =c^{\text {Capex }} \cdot \frac{\left(c^{\text {WACC }} \cdot\left(1+c^{\text {WACC }}\right)^{n}\right.}{\left(\left(1+c^{\text {WACC }}\right)^{n}-1\right)} \\
c^{T I V} & =c^{\text {Capex }} \cdot c^{\text {optimized_capacity }}
\end{aligned}
$$

Figure 8 compares the volatile generators' investment cost, i.e., wind, solar PV, and hydro ROR plants. We see that the total investment cost for the volatile generators in $\mathrm{SH}$ decreases by $76 \%$ ( 4.9 bn $€$ vs. 1.1 bn $€$ ) over the scenarios. The annual investment cost decreases from $262.7 \mathrm{mn} € / \mathrm{yr}$ to $61.5 \mathrm{mn} € / \mathrm{yr}$ with the increasing biomass availability.

Figure 9 compares the investment cost of CHP plants and heat pumps (GSHP and ASHP). Overall, the total investment cost increases by $7 \%$ ( 10.6 bn $€$ vs. 11.3 bn $€$ ) over the scenarios. The annual investment cost increases from $819.2 \mathrm{mn} € / \mathrm{yr}$ in the BM-25 scenario to $853.7 \mathrm{mn} € / \mathrm{yr}$ in the BM-100 scenario. 


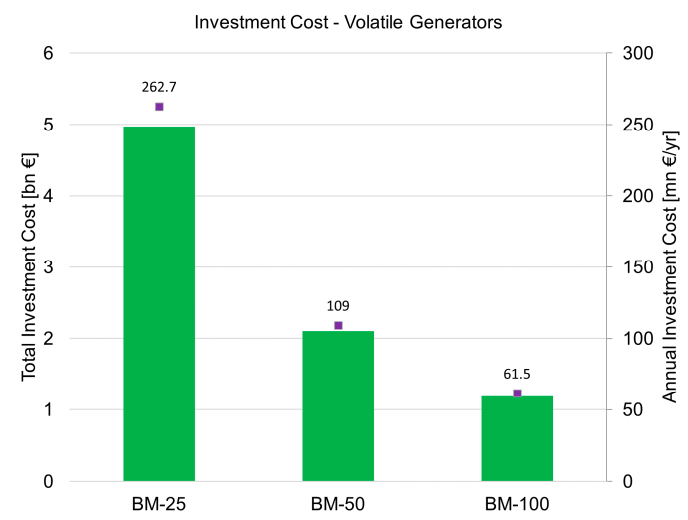

Figure 8. Comparison of volatile generator investments in $\mathrm{SH}$.

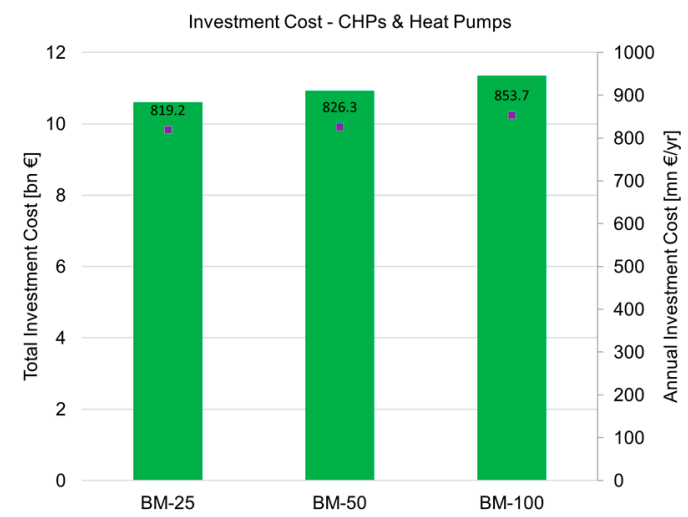

Figure 9. Comparison of combined heat and power (CHP) and heat pump investments in SH.

Figure 10 compares the storages' investment cost, i.e., Li-ion, Redox, $\mathrm{H}_{2}$, ACAES, and TES. The total investment cost for the storages in SH decreases by $69 \%$ ( 4.5 bn $€$ vs. 1.3 bn $€$ ) over the scenarios. The annual investment cost decreases from $357.6 \mathrm{mn} € / \mathrm{yr}$ in the BM-25 scenario to $105.1 \mathrm{mn} € / \mathrm{yr}$ in the BM-100 scenario.

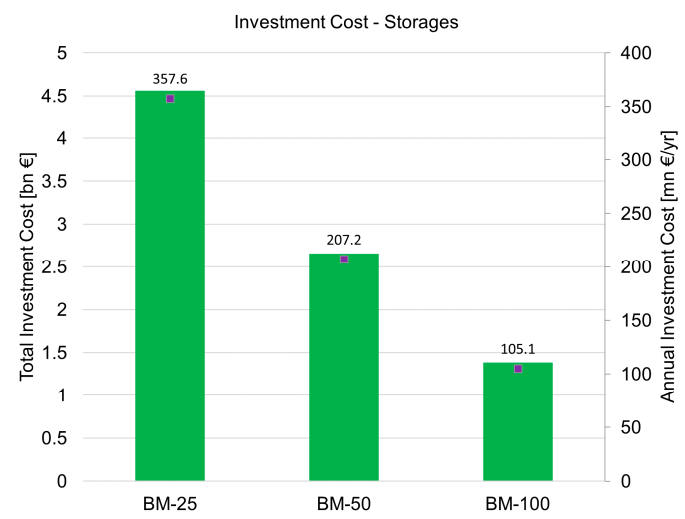

Figure 10. Comparison of storage investments in $\mathrm{SH}$.

The total investment in volatile generators, CHPs, and storages is 20.1 bn $€$ in the BM-25 scenario. The investment decreases by $22 \%$ in the BM-50 scenario (15.6 bn $€$ ) and 30\% in the BM-100 scenario (13.9 bn $€$ ). The annual investment cost decreases accordingly, from 1.44 bn $€ / y r$ in the BM-25 scenario to 1.02 bn $€ / y r$ in the BM-100 scenario. Figure 11 illustrates the total investments for different scenarios from OSeEM-SN optimization results. 


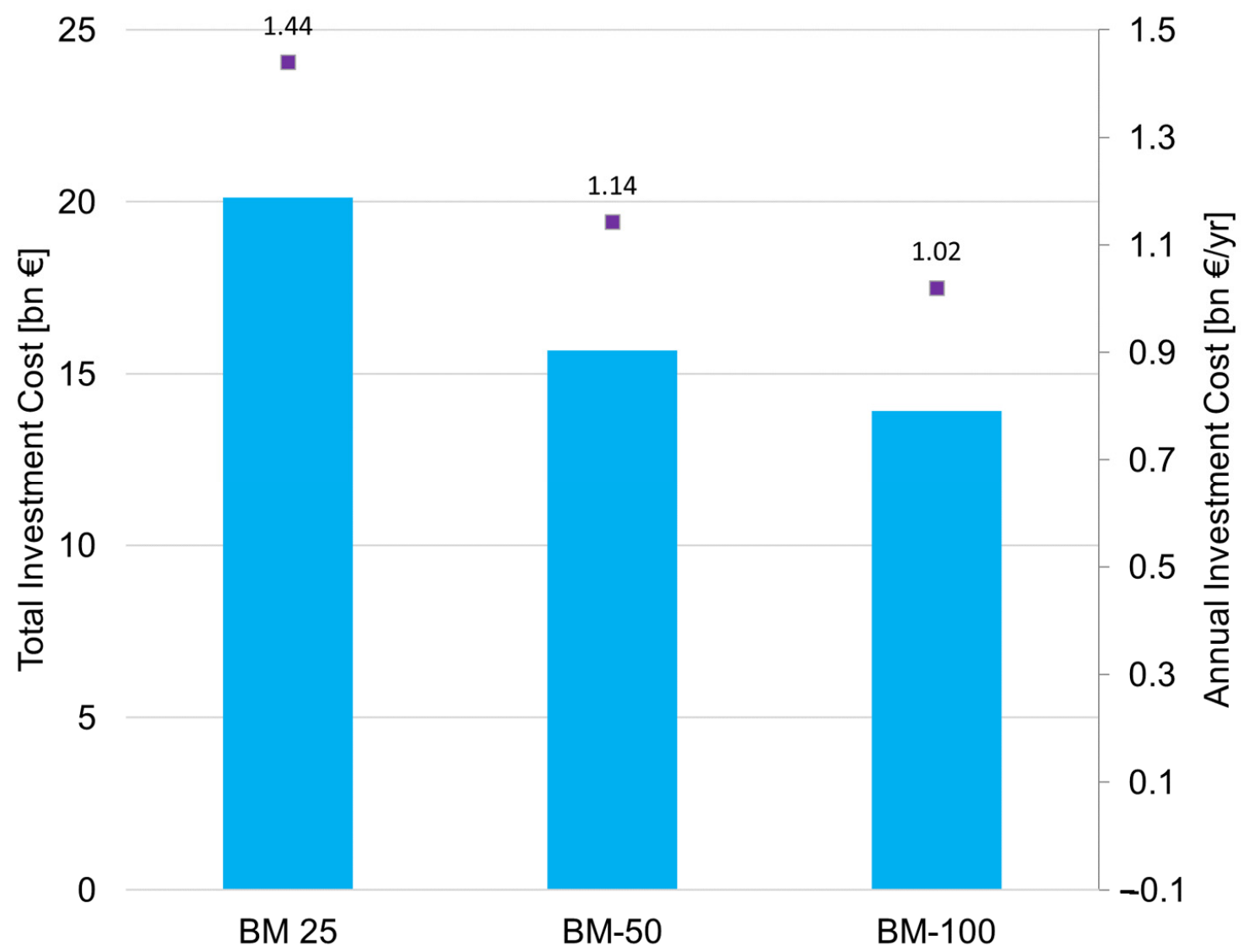

Figure 11. Comparison of total investments (volatile generators, CHPs, and storages) in SH.

\subsubsection{Energy Mix}

Figure 12 compares the energy mix results of the OSeEM-SN model. Figure 12a compares the electricity generation from the combined (i.e., existing and new) capacities. The onshore wind generation dominates the energy mix because of high wind availability in SH. The onshore wind electricity generation varies between $20.9 \mathrm{TWh}_{\mathrm{el}}$ and $26.6 \mathrm{TWh}_{\mathrm{el}}$ for the three scenarios. The model does not suggest installing new offshore capacities, because of two reasons: (i) the cost of offshore is higher, and (ii) the demand is already met using other resources. However, this is only valid for SH's subnational case, where plenty of renewable resources are available. The scenario will be different for a larger case with a lack of adequate renewable resources. The offshore electricity generation from the existing capacities is the same for the three scenarios, $5.5 \mathrm{TWh}_{\mathrm{el}}$. The hydro ROR electricity generation also remains the same, $0.016 \mathrm{TWh}_{\mathrm{el}}$, for all three scenarios. Solar PV-based electricity varies from $8.7 \mathrm{TWh}_{\mathrm{el}}$ in the BM-25 scenario to $4.6 \mathrm{TWh}_{\mathrm{el}}$ in the BM-100 scenario. Overall, the electricity generation decreases by $17 \%\left(42.4 \mathrm{TWh}_{\mathrm{el}} \mathrm{vs} .34 .9 \mathrm{TWh}_{\mathrm{el}}\right)$ from the BM-25 scenario to the BM-100 scenario. Therefore, with high biomass-based CHPs in the energy mix, the curtailment from other variable renewable energy plants can be decreased. Figure $12 \mathrm{~b}$ compares the heat generation from the combined CHP capacities and new heat pump capacities. GSHPs dominate the heat mix; however, the installation of GSHP decreases as the biomass penetrates more into the energy mix. From the BM-25 to the BM-100 scenario, while the CHP-based heat generation increases by $154 \%\left(1.51 \mathrm{TWh}_{\text {th }}\right.$ vs. $\left.3.84 \mathrm{TWh}_{\text {th }}\right)$, the GSHP installation decreases by $28 \%\left(19.8 \mathrm{TWh}_{\text {th }}\right.$ vs. $\left.14.1 \mathrm{TWh}_{\text {th }}\right)$. However, the demand is also complemented by ASHPs, which increase from $1.69 \mathrm{TWh}_{\text {th }}$ in the BM-25 scenario to $4.79 \mathrm{TWh}_{\mathrm{th}}$ in the BM-100 scenario.

The analysis based on OSeEM-SN model results is summarized below:

1. SH has adequate renewable resources to meet its electricity and building heat demands. 
2. The onshore wind dominates electricity generation.

3. Electric heat pumps, mainly GSHPs, dominate heat generation.

4. The batteries offer short-term storage solutions for electricity storage.

5. ACAES, $\mathrm{H}_{2}$, and TES are promising storage solutions, especially when renewable energy availability is limited.

6. Power-to-heat devices, such as GSHP and ASHP, stand out as prominent heating options besides traditional CHPs.

7. TES plays an important role in integrating the power and heat sectors.

8. Increasing biomass in the system impacts other technologies' investment costs and can reduce the overall system cost.

9. The optimization reached feasible solutions without utilizing the full potential of many resources. Therefore, the high amount of available potential, especially offshore wind resources, emerges as a promising alternative for powering up other parts of the country, especially Germany's high energy-consuming industrial southern states.

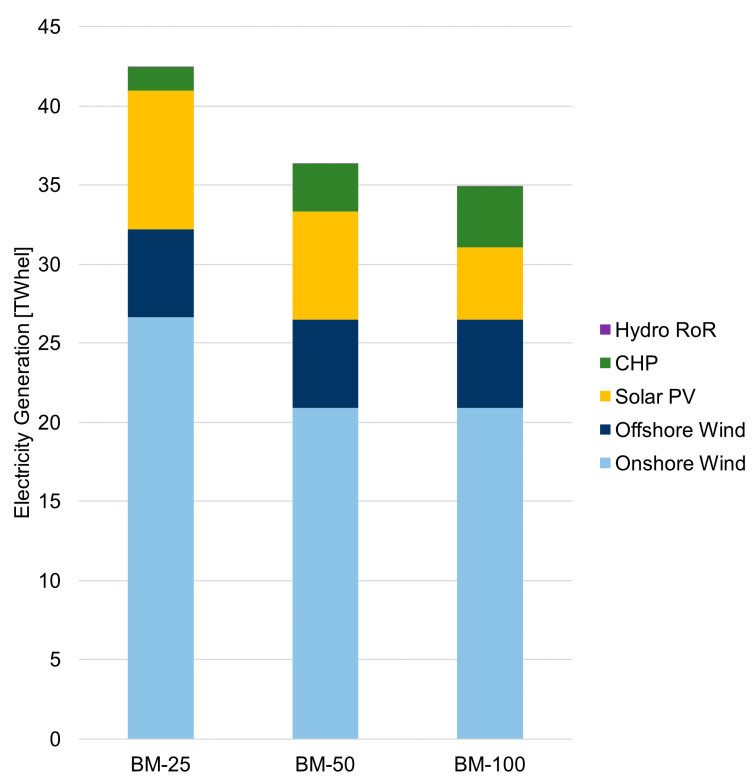

(a)

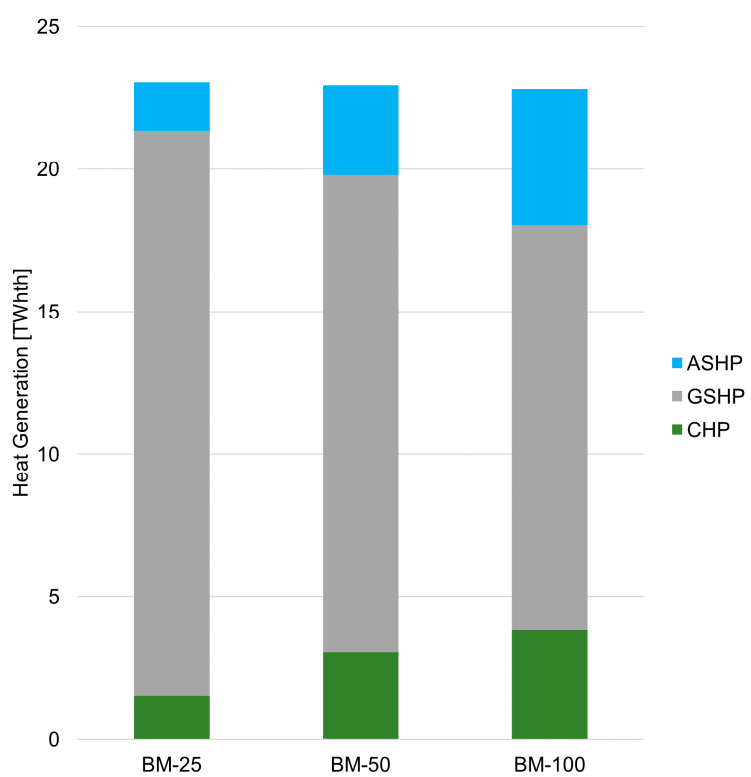

(b)

Figure 12. Energy mix for different scenarios in $\mathrm{SH}$ (a) electricity mix and (b) heat mix.

\section{Discussion}

The increasing penetration of the energy system with predominantly volatile generation units leads to a far-reaching techno-economic and social transformation process. The advancement of the energy transition leads to the fact that power generation plants, instead of being located in the consumer centers' immediate vicinity, are increasingly located in places with the best site conditions for the respective plants. With the increasing feed-in of supply-dependent renewable energy, consumption and generation are falling apart in time, placing new demands on the system. Due to its special location situation, SchleswigHolstein already represents a system that can be considered exemplary for future energy systems, with shares of $100 \%$ renewable energies. Analyses of future energy systems with a very high share of renewable energies, in which consumption and generation must be coordinated, can already be carried out today using Schleswig-Holstein as an example. Schleswig-Holstein can thus already act as a blueprint for future renewable energy systems.

Model-based analyses play a central role in the analysis of such increasingly complex energy systems. In addition to purely technical modeling, open science approaches for the reproducibility of scientific results have become increasingly important in recent years. 
Therefore, models must address the diverse issues in the field of energy system analysis and, at the same time, meet high scientific standards in the sense of open science. To accompany the energy transition's progress and transfer it to the heating sector, an energy model is needed to map the complex interdependencies between the individual sectors. It makes sense to make the model and its databases freely accessible to enable scientists, political decision-makers, entrepreneurs, and citizens, alike, to use and further develop it.

Highly renewable-based energy systems at the subregional level are becoming popular in energy transition studies. Such studies include investigation of $100 \%$ renewable energy systems in Hvar (Croatia) [57], Samsø (Denmark) [58], the Åland Islands (Finland) [59], Orkney (Scotland) [58], the Canary Islands (Spain) [60], California (USA) [61], and New York State (USA) [62]. It is more common to analyze electricity systems than integrated energy systems.

The project aims to develop a source-rich and flexible tool for modeling highly renewable and sector-coupled subnational energy systems and validate them in the context of the Schleswig-Holstein system. The OSeEM-SN model, consisting of scripts and tabular database concepts, was developed to achieve the outlined requirements. The basic concept serves the general description of sector-coupled energy systems. It is based on a graph-theoretical approach, which provides a generic basis for different simulation and optimization models. This concept was implemented within the Oemof framework, using the optimization library Oemof Solph. Comprehensive applications using Oemof are renpass [63], openMod.sh [64], and reegishp [65]. However, their usability is limited. For instance, renpass is an electricity market model, openMod.sh focuses on one region, and reegis $^{h p}$ evaluates district heating and CHP [16]. In contrast, the scope and upgradability of OSeEM-SN are broader and simpler. The model's openness allows other users to actively develop the tool and modification for specific purposes to answer research questions within a subregional framework. The tool is also useful for investigating island energy systems using only renewables. Therefore, the OSeEM-SN model is unique for analyzing power and heat sector-coupled energy systems at the regional level. With the gradual integration of more sectors and upgradation of the model, the tool can be useful for researchers and policymakers to answer energy transition-related questions using a straightforward approach. The development of the OSeEM-SN model confirms the findings by Hilpert et al. [16], i.e., the flexibility in a new tool development using Oemof allows adjustments and changing research objectives, avoiding lock-in effects.

\section{Conclusions}

\subsection{Limitations of the Model}

The model is in its early stage of development, and, therefore, the analysis conducted in this study is subject to certain limitations. Since the results highly depend on the inclusion of different technologies and demands, the results may change based on the newer version of the model with more components and demands. This will also broaden the scope of the model to use it for different geographical contexts. The current version of the OSeEM-SN model does not consider

1. Geothermal, ocean and wave energy, concentrated solar power plants, etc.;

2. Industrial process heating demands;

3. Transmission line modeling;

4. Latent and thermo-chemical heat storages as TES options;

5. Interconnection with neighboring regions;

6. Modeling of electric vehicles, coupling of the transport sector, and provision of vehicle-to-grid charging;

7. Renewable heating options, such as using solar thermal collectors; and

8. Demand response management.

Nevertheless, as a continuous development of the model, future versions will gradually include different technologies, demands, and other components into the model. 


\subsection{Future Plans and Summary of the Study}

The upgradation of OSeEM-SN can be outlined as follows:

1. Grid modeling between subnational regions;

2. Modeling of process heating components in industries;

3. Modeling of district heating components;

4. Inclusion of concentrated solar, geothermal, ocean, and wave energy plants;

5. Inclusion of latent heat and thermo-chemical heat storage plants;

6. Modeling of the transport sector;

7. Modeling of demand response activities; and

8. Development of a graphical user interface.

The following research questions, among others, can be investigated with the upgraded version of the OSeEM-SN model:

1. Which combination of plants is suitable for economic operation?

2. What added value does sector-coupling of the energy sources bring?

3. Which inconsistencies exist in the subregional energy systems?

4. What role may dispatchable loads or CHPs play as flexibility options?

5. How can regional energy markets be designed?

6. Where do key bottlenecks arise in the power grid of a subnational system?

7. How can the industry sector be decarbonized?

8. What role will storage play in a highly renewable and sector-coupled subnational energy model?

This study's main objective is to develop methodologies for building subnational models of 100\% renewable and sector-coupled energy systems. The model used Oemof Tabular to develop a state-of-the-art tool to analyze subnational energy systems. The model consists of the basic renewable resources and storage options to meet the electricity and building heat demands. Oemof Solph's functionalities are used for the core part of the model. Simple Python scripts and tabular data files allow the user to change the model's input details and analyze energy systems for different scenarios.

The study validates the model for Schleswig-Holstein's energy system analysis. The OSeEM-SN model optimized three different scenarios for different available biomass potentials. The model could reach feasible solutions for all three scenarios, indicating the feasibility of a $100 \%$ renewable and power-building, heat-coupled energy system for Schleswig-Holstein. Analysis of the results shows that, with increasing biomass availability, volatile generator investment decreases. The increasing amount of biomass-based CHP plants impacts both the electricity and heat generation mix.

The study also identifies the current limitations of the model. Since the model is based on Oemof, the model's upgradation is possible using different functionalities under the Oemof. The model has been validated with SH's case study, and the results have been analyzed in detail in the study. Therefore, the OSeEM-SN model is presented as a beneficial tool to create different scenarios and examine different possible pathways for subnational energy systems of similar contexts.

Funding: This research is a part of the ENSYSTRA project which received funding from the European Union's Horizon 2020 research and innovation program under the Marie Skłodowska-Curie grant agreement No: 765515.

Institutional Review Board Statement: Not applicable.

Informed Consent Statement: Not applicable.

Data Availability Statement: Data, source codes, and results of the model are available in the following Github repository [66]: https:/ / github.com/znes/OSeEM-SN (accessed on 31 March 2021). 
Acknowledgments: This work was supported by the ENSYSTRA network and by the Center for Sustainable Energy Systems (CSES) in Europa-Universität Flensburg. The author is grateful to have received regular supervision and guidance from Olav Hohmeyer during the ENSYSTRA project. The author would like to thank Andre Harewood for reviewing the language of the article. The author is also thankful to Christian Fleischer and Simon Hilpert for the cooperation throughout the project. The author appreciates the consistent support from his wife, Anika Rahman, during the Covid-19 pandemic's difficult days.

Conflicts of Interest: The author declares no conflict of interest.

\section{Abbreviations}

\begin{tabular}{|c|c|}
\hline Abbreviation & Elaboration \\
\hline ACAES & Adiabatic compressed air energy storage \\
\hline AEE & Agentur für Erneuerbare Energien (Agency for Renewable Energies) \\
\hline AIV & Annual investment cost \\
\hline ASHP & Air source heat pump \\
\hline bn & Billion \\
\hline Capex & Capital expenditure \\
\hline $\mathrm{CHP}$ & Combined heat and power \\
\hline $\mathrm{CO}_{2}$ & Carbon dioxide \\
\hline $\mathrm{COP}$ & Coefficient of performance \\
\hline DHW & Domestic hot water \\
\hline el & Electrical \\
\hline EU & European Union \\
\hline FOM & Fixed operation and maintenance \\
\hline GSHP & Ground source heat pump \\
\hline GW & Gigawatt \\
\hline GWh & Gigawatt-hours \\
\hline $\mathrm{H}_{2}$ & Hydrogen \\
\hline $\mathrm{hr}$ & Hour \\
\hline $\mathrm{kW}$ & Kilowatt \\
\hline $\mathrm{kWh}$ & Kilowatt-hours \\
\hline Li-ion & Lithium-ion \\
\hline LP & Linear Programming \\
\hline MILP & Mixed-Integer Linear Programming \\
\hline $\mathrm{mn}$ & Million \\
\hline MW & Megawatt \\
\hline MWh & Megawatt-hours \\
\hline Oemof & Open Energy Modeling Framework \\
\hline NS & North Sea \\
\hline OSeEM-SN & Open Sector-coupled Energy Model for Subnational Energy Systems \\
\hline PHS & Pumped hydro storage \\
\hline PV & Photovoltaic \\
\hline Redox & Vanadium Redox Flow \\
\hline ROR & Run-of-the-river \\
\hline $\mathrm{SH}$ & Schleswig-Holstein \\
\hline th & Thermal \\
\hline TIV & Total investment cost \\
\hline TW & Terawatt \\
\hline TES & Thermal energy storage \\
\hline TWh & Terawatt-hours \\
\hline VOM & Variable operation and maintenance \\
\hline WACC & Weighted average capital cost \\
\hline yr & Year \\
\hline
\end{tabular}




\section{References}

1. European Commission. Paris Agreement, Climate Action-European Commission. 2016. Available online: https://ec.europa.eu/ clima/policies/international/negotiations/paris_en (accessed on 23 February 2021).

2. European Commission. The European Green Deal. 2019. Available online: https:/ / eur-lex.europa.eu/legal-content/EN/TXT/ ?qid=1596443911913\&uri=CELEX:52019DC0640\#document2 (accessed on 23 February 2021).

3. Robinius, M.; Otto, A.; Heuser, P.; Welder, L.; Syranidis, K.; Ryberg, D.S.; Grube, T.; Markewitz, P.; Peters, R.; Stolten, D. Linking the power and transport sectors-Part 1: The Principle of sector coupling. Energies 2017, 10, 956. [CrossRef]

4. Fridgen, G.; Keller, R.; Körner, M.-F.; Schöpf, M. A holistic view on sector coupling. Energy Policy 2020, 147, 111913. [CrossRef]

5. Bernath, C.; Deac, G.; Sensfuß, F. Impact of sector coupling on the market value of renewable energies-A Model-based scenario analysis. Appl. Energy 2021, 281, 115985. [CrossRef]

6. Pavičević, M.; Mangipinto, A.; Nijs, W.; Lombardi, F.; Kavvadias, K.; Jiménez Navarro, J.P.; Colombo, E.; Quoilin, S. The potential of sector coupling in future European energy systems: Soft linking between the Dispa-SET and JRC-EU-TIMES models. Appl. Energy 2020, 267, 115100. [CrossRef]

7. Martínez-Gordón, R.; Morales-España, G.; Sijm, J.; Faaij, A.P.C. A review of the role of spatial resolution in energy systems modelling: Lessons learned and applicability to the North Sea region. Renew. Sustain. Energy Rev. 2021, 141, 110857. [CrossRef]

8. Gusatu, L.F.; Yamu, C.; Zuidema, C.; Faaij, A.A. Spatial analysis of the potentials for offshore wind farm locations in the North Sea region: Challenges and opportunities. ISPRS Int. J. Geo Inf. 2020, 9, 96. [CrossRef]

9. Gorenstein Dedecca, J.; Hakvoort, R.A. A review of the North Seas offshore grid modeling: Current and future research. Renew. Sustain. Energy Rev. 2016, 60, 129-143. [CrossRef]

10. TNO. Integration of North Sea Energy Systems Saves Billions. 2019. Available online: https://www.tno.nl/en/focus-areas/ energy-transition/roadmaps/system-transition/towards-a-reliable-affordable-and-fair-energy-system/energy-conversionand-storage/integration-of-north-sea-energy-systems-saves-billions/ (accessed on 20 March 2021).

11. ENSYSTRA-Energy Systems in Transition EU H2020 Research Project. 2018. Available online: https://ensystra.eu/ (accessed on 20 March 2021).

12. Horschig, T.; Thrän, D. Are decisions well supported for the energy transition? A review on modeling approaches for renewable energy policy evaluation. Energy Sustain. Soc. 2017, 7, 5. [CrossRef]

13. Simoes, S.; Zeyringer, M.; Mayr, D.; Huld, T.; Nijs, W.; Schmidt, J. Impact of different levels of geographical disaggregation of wind and PV electricity generation in large energy system models: A case study for Austria. Renew. Energy 2017, 105, 183-198. [CrossRef]

14. Kerimray, A.; Suleimenov, B.; De Miglio, R.; Rojas-Solórzano, L.; Amouei Torkmahalleh, M.; Gallachóir, B.P.Ó. Investigating the energy transition to a coal free residential sector in Kazakhstan using a regionally disaggregated energy systems model. J. Clean. Prod. 2018, 196, 1532-1548. [CrossRef]

15. Bhattacharyya, S.C.; Timilsina, G.R. A review of energy system models. Int. J. Energy Sect. Manag. 2010, 4, 494-518. [CrossRef]

16. Hilpert, S.; Kaldemeyer, C.; Krien, U.; Günther, S.; Wingenbach, C.; Plessmann, G. The Open Energy Modelling Framework (OEMOF)-A new approach to facilitate open science in energy system modelling. Energy Strategy Rev. 2018, 22, 16-25. [CrossRef]

17. Nagel, J. Modeling optimization problems in the energy sector with OEMOF. In Optimization of Energy Supply Systems: Modelling, Programming and Analysis; Nagel, J., Ed.; Springer International Publishing: Cham, Switzerland, 2019; pp. 257-294. [CrossRef]

18. Hilpert, S.; Günther, S.; Kaldemeyer, C.; Krien, U.; Plessmann, G.; Wiese, F.; Wingenbach, C. Addressing energy system modelling challenges: The Contribution of the Open Energy Modelling Framework (oemof). Preprints 2017. [CrossRef]

19. Hilpert, S.; Kaldemeyer, C.; Wiese, F.; Plessmann, G. A qualitative evaluation approach for energy system modelling softwareCase study results for the Open Energy Modelling Framework (oemof). Energy Sustain. Soc. 2017. [CrossRef]

20. Maruf, M.N.I. Sector coupling in the North Sea region-A review on the energy system modelling perspective. Energies 2019, 12, 4298. [CrossRef]

21. Landesportal Schleswig-Holstein, Versorgungsbeitrag der Erneuerbaren Energien. Contribution to the Supply of Renewable Energies. 2021. Available online: http:/ / www.schleswig-holstein.de/DE/Landesregierung/Themen/Energie/Energiewende/ Daten/_documents/versorgungsbeitrag.html?nn=34ea8660-9025-4fe4-ab51-2c5a6b2b144b (accessed on 24 February 2021).

22. Meyer, B.; Tietje, D.H. Erneuerbare Energien in Zahlen für Schleswig-Holstein, Statistisches Amt für Hamburg und SchleswigHolstein, Kiel, Germany. 2020. Available online: https:/ / www.schleswig-holstein.de/DE/Landesregierung/Themen/Energie/ Energiewende/Daten/pdf/EE_Bilanz_2018.pdf?_blob=publicationFile\&v=3 (accessed on 24 February 2021).

23. Ringkjøb, H.-K.; Haugan, P.M.; Solbrekke, I.M. A review of modelling tools for energy and electricity systems with large shares of variable renewables. Renew. Sustain. Energy Rev. 2018, 96, 440-459. [CrossRef]

24. Open Models. 2021. Available online: https://wiki.openmod-initiative.org/wiki/Open_Models\#List_of_models (accessed on 23 March 2021).

25. Pfenninger, S.; Pickering, B. Calliope: A multi-scale energy systems modelling framework. J. Open Source Softw. 2018,3 , 825. [CrossRef]

26. DESSTINEE Model 2050. 2015. Available online: https://sites.google.com/site/2050desstinee/getting-the-model (accessed on 23 March 2021).

27. The Dispa-SET Model. 2019. Available online: http:/ / www.dispaset.eu/en/latest/ (accessed on 23 March 2021). 
28. Egerer, J. Open Source Electricity Model for Germany (ELMOD-DE); DIW Berlin, German Institute for Economic Research: Berlin, Germany, 2016; Available online: https://ideas.repec.org/p/diw/diwddc/dd83.html (accessed on 23 March 2021).

29. Ficus: A (Mixed Integer) Linear Optimisation Model for Local Energy Systems. 2018. Available online: https://ficus.readthedocs. io/en/latest/ (accessed on 23 March 2021).

30. LEAP. The Low Emissions Analysis Platform. 2020. Available online: https:/ / leap.sei.org/default.asp (accessed on 23 March 2021).

31. KU Leuven. LUSYM: A Unit Commitment Model Formulated as a Mixed-Integer Linear Program. 2015. Available online: https:/ / www.mech.kuleuven.be/en/tme/research/energy_environment/Pdf/wpen2014-7.pdf (accessed on 23 March 2021).

32. Medeas. Modeling the Renewable Energy Transition in Europe. 2021. Available online: https://www.medeas.eu/ (accessed on 23 March 2021).

33. OSeMOSYS-The Open Source Energy Modelling System. 2021. Available online: https://github.com/OSeMOSYS/OSeMOSYS (accessed on 23 March 2021).

34. Svendsen, H.G.; Spro, O.C. PowerGAMA: A new simplified modelling approach for analyses of large interconnected power systems, applied to a 2030 Western Mediterranean case study. J. Renew. Sustain. Energy 2016, 8. [CrossRef]

35. PyPSA. Python for Power System Analysis. PyPSA. 2021. Available online: https://github.com/PyPSA/PyPSA (accessed on 23 March 2021).

36. RETScreen. 2021. Available online: https://www.nrcan.gc.ca/maps-tools-and-publications/tools/modelling-tools/retscreen/ 7465 (accessed on 23 March 2021).

37. Modelling Overview SIREN Toolkit-Sustainable Energy Now WA. 2014. Available online: https://www.sen.asn.au/modelling overview (accessed on 23 March 2021).

38. Switch Power System Planning Model. GitHub. 2021. Available online: https://github.com/switch-model (accessed on 23 March 2021).

39. Dorfner, J. Urbs: A Linear Optimisation Model for Distributed Energy Systems. Chair of Renewable and Sustainable Energy Systems. 2021. Available online: https:/ / github.com/tum-ens/urbs (accessed on 23 March 2021).

40. Oemof, Open Energy Modelling Framework. GitHub. 2021. Available online: https:/ / github.com/oemof (accessed on 23 March 2021).

41. Krien, U.; Schönfeldt, P.; Launer, J.; Hilpert, S.; Kaldemeyer, C.; Pleßmann, G. Oemof.solph—A model generator for linear and mixed-integer linear optimisation of energy systems. Softw. Impacts 2020, 6, 100028. [CrossRef]

42. Hilpert, S.; Günther, S.; Söthe, M. Oemof Tabular, Europa-Universität Flensburg, Flensburg, Germany. 2020. Available online: https://github.com/oemof/ oemof-tabular (accessed on 8 July 2020).

43. Maruf, M.N.I. Open model-based analysis of a 100\% renewable and sector-coupled energy system-The case of Germany in 2050. Appl. Energy 2021, 288, 116618. [CrossRef]

44. Hilpert, S. Effects of decentral heat pump operation on electricity storage requirements in Germany. Energies 2020, $13,2878$. [CrossRef]

45. Brown, T.; Schlachtberger, D.; Kies, A.; Schramm, S.; Greiner, M. Synergies of sector coupling and transmission reinforcement in a cost-optimised, highly renewable European energy system. Energy 2018, 160, 720-739. [CrossRef]

46. Pfenninger, S.; Staffell, I. Renewables.Ninja. 2020. Available online: https:/ / www.renewables.ninja/ (accessed on 22 July 2020).

47. Kavvadias, K.; Hidalgo Gonzalez, I.; Zucker, A.; Quoilin, S. Dispa-SET, Energy Modelling Toolkit. 2020. Available online: https://github.com/energy-modelling-toolkit/Dispa-SET (accessed on 22 July 2020).

48. Wiese, F.; Schlecht, I.; Bunke, W.-D.; Gerbaulet, C.; Hirth, L.; Jahn, M.; Kunz, F.; Lorenz, C.; Mühlenpfordt, J.; Reimann, J.; et al. Open power system data-Frictionless data for electricity system modelling. Appl. Energy 2019, 236, 401-409. [CrossRef]

49. ENTSO-e. Power Statistics. 2020. Available online: https:/ / www.entsoe.eu/data/power-stats / (accessed on 17 July 2020).

50. Ruhnau, O. When2Heat Heating Profiles. 2019. Available online: https://data.open-power-system-data.org/when2heat/ (accessed on 31 March 2021). [CrossRef]

51. Scaramuzzino, C.; Garegnani, G. Hotmaps Project Data on Potential Biomass-NUTS3 Level. Available online: https://gitlab com/hotmaps/potential/potential_biomass (accessed on 22 July 2020).

52. CSES. Input Data for the ANGUS II Project. 2020. Available online: https://github.com/ZNES-datapackages/angus-input-data (accessed on 6 August 2020).

53. Deutsche WindGuard GmbH. 2021. Available online: https:/ /www.windguard.de (accessed on 26 February 2020).

54. AEE. Facts and Figures on the Development of Renewable Energies in Individual Federal States. 2020. Available online: https://www.foederal-erneuerbar.de/landesinfo/bundesland (accessed on 22 July 2020).

55. Osorio, S.; Pietzcker, R.; Tietjen, O. Documentation of LIMES-EU-A Long-Term Electricity System Model for Europe, 93; Potsdam Institute for Climate Impact: Potsdam, Germany, 2021; Available online: https:/ /www.pik-potsdam.de/en/institute/departments / transformation-pathways/models/limes/model-documentation-v2.37 (accessed on 4 March 2021).

56. Vattenfall. Power Plants: Pumpspeicherkraftwerk Geesthacht. 2020. Available online: https://powerplants.vattenfall.com/de/ geesthacht (accessed on 26 February 2021).

57. Bačelić Medić, Z.; Ćosić, B.; Duić, N. Sustainability of remote communities: $100 \%$ renewable island of Hvar. J. Renew. Sustain. Energy 2013, 5, 041806. [CrossRef] 
58. Marczinkowski, H.M.; Østergaard, P.A. Evaluation of electricity storage versus thermal storage as part of two different energy planning approaches for the islands Samsø and Orkney. Energy 2019, 175, 505-514. [CrossRef]

59. Child, M.; Nordling, A.; Breyer, C. Scenarios for a sustainable energy system in the Åland Islands in 2030. Energy Convers. Manag. 2017, 137, 49-60. [CrossRef]

60. Gils, H.C.; Simon, S. Carbon neutral archipelago-100\% renewable energy supply for the Canary Islands. Appl. Energy 2017, 188, 342-355. [CrossRef]

61. Jacobson, M.Z.; Delucchi, M.A.; Ingraffea, A.R.; Howarth, R.W.; Bazouin, G.; Bridgeland, B.; Burkart, K.; Chang, M.; Chowdhury, N.; Cook, R.; et al. A roadmap for repowering California for all purposes with wind, water, and sunlight. Energy 2014, 73, 875-889. [CrossRef]

62. Jacobson, M.Z.; Howarth, R.W.; Delucchi, M.A.; Scobie, S.R.; Barth, J.M.; Dvorak, M.J.; Klevze, M.; Katkhuda, H.; Miranda, B.; Chowdhury, N.A.; et al. Examining the feasibility of converting New York State's all-purpose energy infrastructure to one using wind, water, and sunlight. Energy Policy 2013, 57, 585-601. [CrossRef]

63. Center for Sustainable Energy Systems (ZNES). Renpass, Renewable Energy Pathway Simulation System. 2015. Available online: https:/ / github.com/znes/renpass (accessed on 23 March 2021).

64. Center for Sustainable Energy Systems (ZNES). OpenMod.sh, the Open Energy Model for Schleswig-Holstein. 2018. Available online: https:/ / github.com/znes/openmod.sh (accessed on 23 March 2021).

65. Reiner Lemoine Institut. Reegishp, an Oemof Application to Model Local Heat and Power Systems. 2016. Available online: https:/ / github.com/rl-institut/smenos (accessed on 23 March 2021).

66. Maruf, M.N.I. OSeEM-SN, Open Sector-Coupled Energy Model for Sub-National Energy Systems, GitHub. 2021. Available online: https:/ / github.com/znes/OSeEM-SN (accessed on 3 March 2021). 